\title{
Hypoxia and Hypoxia-Inducible Factor Signaling in Muscular Dystrophies: Cause and Consequences
}

\author{
Thuy-Hang Nguyen ${ }^{1}$, Stephanie Conotte ${ }^{1}$, Alexandra Belayew ${ }^{1} \mathbb{D}$, Anne-Emilie Declèves ${ }^{2}{ }^{\mathbb{D}}$, Alexandre Legrand ${ }^{1}$ \\ and Alexandra Tassin 1,*(D) \\ 1 Laboratory of Respiratory Physiology, Pathophysiology and Rehabilitation, Research Institute for Health \\ Sciences and Technology, University of Mons, 7000 Mons, Belgium; thuyhang.nguyen@umons.ac.be (T.-H.N.); \\ stephanie.conotte@outlook.com (S.C.); alexandra.belayew@umons.ac.be (A.B.); \\ alexandre.legrand@umons.ac.be (A.L.) \\ 2 Department of Metabolic and Molecular Biochemistry, Research Institute for Health Sciences and Technology, \\ University of Mons, 7000 Mons, Belgium; anne-emilie.decleves@umons.ac.be \\ * Correspondence: alexandra.tassin@umons.ac.be
}

Citation: Nguyen, T.-H.; Conotte, S.; Belayew, A.; Declèves, A.-E.; Legrand, A.; Tassin, A. Hypoxia and

Hypoxia-Inducible Factor Signaling in Muscular Dystrophies: Cause and Consequences. Int. J. Mol. Sci. 2021, 22, 7220. https://doi.org/10.3390/ ijms 22137220

Academic Editor: Jung-Ae Kim

Received: 31 May 2021

Accepted: 30 June 2021

Published: 5 July 2021

Publisher's Note: MDPI stays neutral with regard to jurisdictional claims in published maps and institutional affiliations.

Copyright: (c) 2021 by the authors. Licensee MDPI, Basel, Switzerland. This article is an open access article distributed under the terms and conditions of the Creative Commons Attribution (CC BY) license (https:// creativecommons.org/licenses/by/ $4.0 /)$.

\begin{abstract}
Muscular dystrophies (MDs) are a group of inherited degenerative muscle disorders characterized by a progressive skeletal muscle wasting. Respiratory impairments and subsequent hypoxemia are encountered in a significant subgroup of patients in almost all MD forms. In response to hypoxic stress, compensatory mechanisms are activated especially through Hypoxia-Inducible Factor $1 \propto(\mathrm{HIF}-1 \alpha)$. In healthy muscle, hypoxia and HIF-1 $\alpha$ activation are known to affect oxidative stress balance and metabolism. Recent evidence has also highlighted HIF-1 $\alpha$ as a regulator of myogenesis and satellite cell function. However, the impact of HIF-1 $\alpha$ pathway modifications in MDs remains to be investigated. Multifactorial pathological mechanisms could lead to HIF-1 $\alpha$ activation in patient skeletal muscles. In addition to the genetic defect per se, respiratory failure or blood vessel alterations could modify hypoxia response pathways. Here, we will discuss the current knowledge about the hypoxia response pathway alterations in MDs and address whether such changes could influence MD pathophysiology.
\end{abstract}

Keywords: hypoxia; myopathies; HIF-1 $\alpha$

\section{Introduction}

Muscular dystrophies (MDs) are a heterogeneous group of inherited degenerative muscle disorders resulting in progressive muscle weakness and dystrophic histopathology observed on muscle biopsies. Clinically, MDs are characterized by a high variability in terms of age of onset, severity, and progression. MDs are also very heterogeneous in their genetic features and the distribution of the affected muscles, including or not an impact on cardiac or respiratory muscles as well as extra-muscular manifestations such as insulin resistance.

Respiratory impairments are frequent MD clinical manifestations and associated to hypoxemia in subgroups of patients [1-3]. At the tissue level, hypoxemia leads to cellular hypoxia. In primary muscle disorders, the impact of hypoxia on muscle pathophysiology remains poorly documented [4]. This is particularly surprising since several MDs are known to cause chronic hypoxemia due to hypoventilation as a consequence of respiratory muscle weakness.

The Nobel prize in Physiology or Medicine was awarded in 2019 to William G. Kaelin Jr, Peter J. Ratcliffe and Gregg L. Semenza "for their discoveries of how cells sense and adapt to oxygen availability" [5]. They uncovered the main effectors of the hypoxic response, the HIF transcription factor family, and how oxygen-dependent post-translational modifications of HIF-1/2 $\alpha$ lead to their degradation in normoxic conditions and their activation in hypoxia. HIF factors (HIF-1, HIF-2, HIF-3) are heterodimers composed of an 
oxygen-regulated $\alpha$ subunit and a stable $\beta$ subunit. HIF- $1 \alpha$ and HIF- $2 \alpha$ are considered as the master regulators of the hypoxic response transcriptional program. Under normoxic conditions, $\mathrm{HIF} \alpha$ subunits are constantly expressed but rapidly degraded by a complex mechanism. They are first hydroxylated by specific Prolyl Hydroxylase Domain-containing enzymes (PHD). This reaction is oxygen-dependent, since the transferred hydroxyl group is derived from the $\mathrm{O}_{2}$ molecule. This reaction also requires three cofactors, namely 2-oxoglutarate, vitamin C, and iron [6]. Then, the Von Hippel-Lindau (pVHL) E3 ubiquitinligase recognizes hydroxylated $\mathrm{HIF} \alpha$ forms and activates their ubiquitination leading to their degradation by the proteasome. By contrast, under hypoxic conditions, PHD cannot hydroxylate $\mathrm{HIF} \alpha$ because of the decreased $\mathrm{O}_{2}$ availability, allowing for HIF $\alpha$ stabilization, dimerization with HIF1 $\beta$, and translocation into the nucleus. HIF factors then activate the transcription of more than a hundred target genes through their binding to a specific DNA sequence called Hypoxia Response Element (HRE) [7-10] (Figure 1 and Table 1). HIF- $1 \alpha$ and HIF- $2 \alpha$ belong to the basic helix-loop-helix (bHLH) family of transcription factors and exhibit a highly conserved structure and functional similarities. However, an increasing number of studies point to differences in transcriptional regulation and function in response to hypoxia and in disease states [11]. The role of HIF-3 is still debated since its gene can express multiple variants exhibiting different activities, some of which were reported as negative regulators of HIF-1/2 $\alpha$ [12].

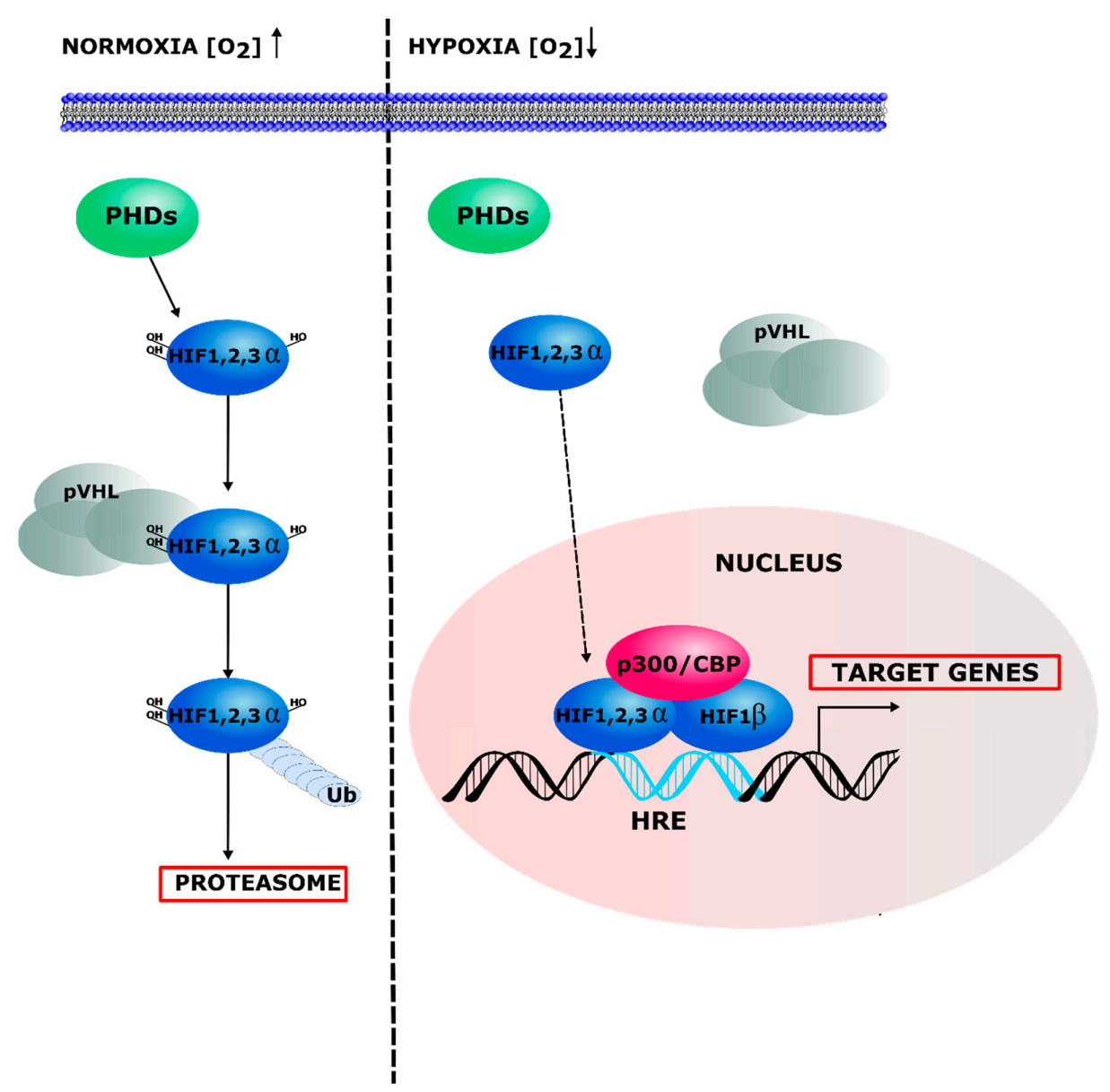

Figure 1. Regulation of HIF pathway. Under normoxia, HIF $\alpha$ protein is hydroxylated by PHDs and subsequently recognized by $\mathrm{pVHL}$ and degraded through the ubiquitinproteasome pathway. In hypoxia, PHD activity is inhibited by the decreased $\mathrm{O}_{2}$ levels and thus HIF $\alpha$ hydroxylation. HIF $\alpha$ is therefore stabilized and translocated into the nucleus, dimerizes with HIF1 $\beta$, and activates the expression of hypoxia responsive genes with additional transcriptional co-factors, such as $\mathrm{CBP} / \mathrm{P} 300 . \mathrm{Ub}=$ ubiquitin. 
Table 1. Main HIF-1 $\alpha$ target genes and regulated pathways.

\begin{tabular}{cc}
\hline Regulated Pathways & HIF-1 $\boldsymbol{\alpha}$ Target Genes \\
\hline Angiogenesis and erythropoiesis & VEGF and VEGF receptor FLT1, \\
heme oxygenase 1, NOS 2 and 3, PDGF
\end{tabular}

Compared to other oxygen-sensitive tissues such as the brain and heart, skeletal muscles tolerate hypoxia quite well because of their plasticity. Indeed, they adapt their metabolism and structural features (fiber size, muscle fiber type, mitochondrial activity, myoglobin content) as well as blood supply (capillary density) in response to hypoxia, a condition muscles encounter in non-pathological contexts e.g., physical exercise or exposure to high altitude [13-15]. Obviously, muscle adaptation will strongly depend on exercise training duration and modalities (resistive vs. endurant). While muscle response to hypoxia has been studied in physiological conditions [16,17], the causes and consequences of hypoxia or HIF- $1 \alpha$ pathway activation in the particular context of MDs remain to be clarified. In this review, we provide an overview of the potential causes of hypoxia in skeletal muscle dystrophies. We also address how hypoxia or HIF- $1 \alpha$ pathway activation may influence skeletal muscle pathophysiology in MDs and discuss potential avenues for future investigations and therapeutic options.

\section{Causes of Hypoxia and HIF-1 $\alpha$ Pathway Activation in MDs}

\subsection{Respiratory Complications in Muscular Dystrophy}

Respiratory failure is a common feature in almost all forms of MDs and the main cause of death in these patients, together with heart dysfunction (see Figure 2 and Table 2). It is defined as the inability to perform adequately the fundamental function of the respiratory system: i.e., to provide proper oxygenation (referred to as oxygenation failure) and carbon dioxide elimination (referred to as ventilatory failure). Negative impact on respiratory functions considerably impairs life quality and adds to the disease burden. While the onset and the degree of respiratory impairment are variable according to the MD form and progression, they are generally described to develop with disease severity and after ambulation loss. It is also important to mention that, even among patients with the same genetic disorder, there is a high variability in the age of onset, severity and progression of the respiratory impairment [1,18-22]. Indeed, in some MDs such as Duchenne Muscular Dystrophy (DMD), Myotonic Dystrophy (DM) or Limb-Girdle Muscular Dystrophy (LGMD), respiratory alterations appear at an early stage of the disease and are a part of the pathological phenotype itself and a major cause of mortality and morbidity. However, in MDs such as Facioscapulohumeral Muscular Dystrophy (FSHD) and Emery-Dreifuss Muscular Dystrophy (EDMD), respiratory troubles are associated with long lasting or severe disease [22]. 


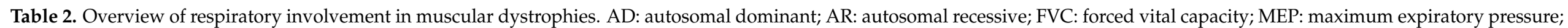

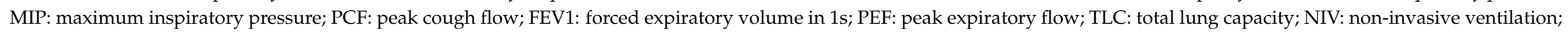

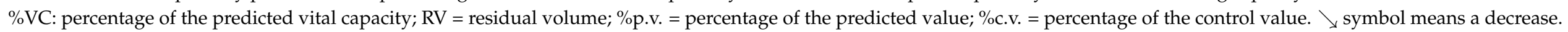

\begin{tabular}{|c|c|c|c|c|c|c|}
\hline \multirow{2}{*}{ Muscular Dystrophy } & \multicolumn{2}{|c|}{ Pathogenetic Factors } & \multicolumn{2}{|c|}{ Clinical Characteristics } & \multicolumn{2}{|r|}{ Respiratory Impairment } \\
\hline & Inheritance & Affected Gene(s) & Muscle Distribution & $\begin{array}{c}\text { Extra-Muscle } \\
\text { Manifestations }\end{array}$ & Frequency & Type \\
\hline \multicolumn{7}{|c|}{ Early onset } \\
\hline Laminin-deficient muscular dystrophy & $\mathrm{AR}$ & LAMA2 & Primarily upper limbs & $\begin{array}{l}\text { Diffuse white matter } \\
\text { hyperintensities on brain } \\
\text { MRI and seizures }\end{array}$ & $\begin{array}{c}\text { Frequent }(30 \% \text { of } \\
\text { patients with complete } \\
\text { laminin-a2 deficiency) } \\
{[25]}\end{array}$ & $\begin{array}{l}\text { Skeletal muscle weakness (including intercostal and } \\
\text { accessory muscles), scoliosis and decreased chest wall } \\
\text { compliance. } \\
\text { Alveolar hypoventilation, mucus plugs with bronchial } \\
\text { obstruction and atelectasis } \\
\searrow \text { FVC (59 patients) [26] }\end{array}$ \\
\hline $\begin{array}{l}\text { SEPN1 myopathy (muscular dystrophy } \\
\text { with rigid spine syndrome) }\end{array}$ & $\mathrm{AR}$ & SEPN1 & $\begin{array}{l}\text { Early rigidity of the spine } \\
\text { and joint contractures of } \\
\text { the ankle and elbow }\end{array}$ & Rigid spine, scoliosis & $\begin{array}{c}\text { Frequent; early } \\
81.7 \% \text { requiring } \\
\text { ventilation (132 patients) } \\
{[27]}\end{array}$ & $\begin{array}{c}\text { Diaphragmatic weakness } \\
\searrow \text { FVC by } 24 \pm 7 \% \text { (7 patients) [28] }\end{array}$ \\
\hline Ullrich muscular dystrophy & AR & $\begin{array}{l}\text { COL6A1, COL6A2, } \\
\text { COL6A3 }\end{array}$ & $\begin{array}{l}\text { Primarily axial and limb } \\
\text { muscles }\end{array}$ & $\begin{array}{l}\text { Rigid spine, laxity of } \\
\text { distal joints }\end{array}$ & Frequent; early & $\begin{array}{l}\text { Diaphragmatic weakness } \\
\searrow \% \mathrm{VC} \text { (40 patients) [29] }\end{array}$ \\
\hline \multicolumn{7}{|c|}{ Childhood and Adult } \\
\hline Duchenne muscular dystrophy & X-linked R & Dystrophin & $\begin{array}{l}\text { Proximal lower limb and } \\
\text { truncal weakness, followed } \\
\text { by of upper limb and distal } \\
\text { muscle weakness }\end{array}$ & $\begin{array}{l}\text { Educational and } \\
\text { psychosocial issue, } \\
\text { scoliosis, } \\
\text { cardiomyopathy and } \\
\text { arrhythmias }\end{array}$ & Frequent & $\begin{array}{l}\text { Vital capacity (\% predicted) decreases linearly, due to } \\
\text { inspiratory and expiratory muscle weakness. } \\
\text { Obstructive sleep apnea and hypoventilation. } \\
\text { Nocturnal desaturation correlated to the severity of } \\
\text { scoliosis. } \\
\searrow \text { FVC, FEV1 and PEF (115 subjects) [30] }\end{array}$ \\
\hline Becker muscular dystrophy & X-linked R & Dystrophin & $\begin{array}{l}\text { Same as DMD but with a } \\
\text { milder phenotype }\end{array}$ & $\begin{array}{l}\text { Less common than in } \\
\text { DMD }\end{array}$ & Rare & $\begin{array}{l}\text { Lung restriction sometimes occurs } \\
\text { but less severe than in DMD }\end{array}$ \\
\hline Emery-Dreifuss muscular dystrophy & $\begin{array}{l}\text { Variable depending on } \\
\text { type }\end{array}$ & $\begin{array}{l}\text { EMD, FHL1, LMNA, } \\
\text { SYNE1, SYNE2 }\end{array}$ & $\begin{array}{l}\text { Slowly and progressive } \\
\text { humeroperoneal pattern }\end{array}$ & $\begin{array}{l}\text { Cardiac conduction } \\
\text { block, insulin resistance, } \\
\text { rigid spine }\end{array}$ & $\begin{array}{l}\text { Frequent; typically in } \\
\text { adulthood }\end{array}$ & $\begin{array}{l}\text { Restrictive pattern of respiratory impairment } \\
\searrow \text { FVC to } 60 \text { and } 45 \% \text { p.v. (measured in } 2 \text { patients) [31] }\end{array}$ \\
\hline
\end{tabular}


Table 2. Cont.

\begin{tabular}{|c|c|c|c|c|c|c|c|}
\hline \multirow{2}{*}{\multicolumn{2}{|c|}{ Muscular Dystrophy }} & \multirow{2}{*}{\multicolumn{2}{|c|}{ Pathogenetic Factors }} & \multirow{2}{*}{\multicolumn{2}{|c|}{ Clinical Characteristics }} & \multicolumn{2}{|r|}{ Respiratory Impairment } \\
\hline & & & & & & & \\
\hline $\begin{array}{l}\text { Facioscapulohumeral } \\
\text { dystrophy }\end{array}$ & FSHD1 & $\mathrm{AD}$ & DUX4, & $\begin{array}{l}\text { Facial, } \\
\text { shoulder, scapular, arm } \\
\text { progressive and } \\
\text { asymmetric weakness }\end{array}$ & $\begin{array}{l}\text { Retinal vasculopathy } \\
\text { and symptomatic } \\
\text { sensorineural hearing } \\
\text { loss }\end{array}$ & $\begin{array}{l}\text { First described as } \\
\text { uncommon, } 1-3 \% \\
\text { require NIV [32]. } \\
\searrow \text { FVC in } 38.3 \% \text { and } \\
\text { severely restrictive in } \\
14.9 \%[33] \text {. }\end{array}$ & $\begin{array}{c}\text { Expiratory and diaphragmatic muscle weakness and } \\
\text { obstructive sleep apnea } \\
\text { mean FVC to } 69 \% \text { p.v. in non-mild disease (40.2\%p.v. } \\
\text { in early onset), minimum } 33 \% \text { p.v. (adult) and } 11 \% \text { p.v. } \\
\text { (early onset) [33] } \\
\searrow \text { MIP (69\%c.v.), MEP (53\%c.v.) and PCF (60\%c.v.) [34] }\end{array}$ \\
\hline \multicolumn{2}{|c|}{ Limb girdle muscular dystrophies } & $\begin{array}{l}\text { AR more frequent than } \\
\qquad \mathrm{AD}\end{array}$ & $\begin{array}{c}\text { Sarcoglycan, } \\
\text { Dystroglycan, } \\
\text { Telethonin, Titin, etc. }\end{array}$ & $\begin{array}{l}\text { Variable but mostly } \\
\text { proximal weakness }\end{array}$ & $\begin{array}{l}\text { Cardiomoypathy } \\
\text { (common in sarcoglycan } \\
\text { deficiency and } \\
\text { dystroglycano pathy) }\end{array}$ & Common in sarcoglycan & $\begin{array}{l}\text { Respiratory insufficiency due to diaphragmatic } \\
\text { weakness } \\
\text { Restrictive pulmonary syndrome indicated by } \\
\text { TLC }<80 \% \text { p.v. (13/38 patients) [35] } \\
\text { FVC below } 40 \% \text { p.v. (20/38 patients) } \\
\searrow \text { PEF (38 patient study) }\end{array}$ \\
\hline \multicolumn{2}{|c|}{ Myotonic dystrophy } & $\mathrm{AD}$ & DMPK, CNBP & $\begin{array}{l}\text { Distal slowly progressive } \\
\text { weakness }\end{array}$ & $\begin{array}{l}\text { Cardiac dysrhythmia, } \\
\text { particularly heart block }\end{array}$ & Common & $\begin{array}{l}\text { Sleep apnea syndrome and } \\
\text { excessive daytime sleepiness } \\
\searrow \text { MEP (21 patient study) [36] } \\
\searrow \text { FVC, VC, TLC, RV, FEV1 [37] }\end{array}$ \\
\hline
\end{tabular}




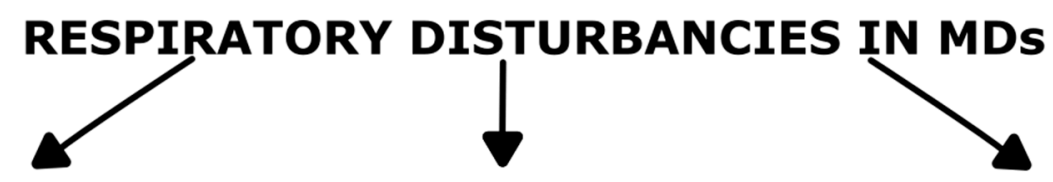

1.LUNG FAILURE

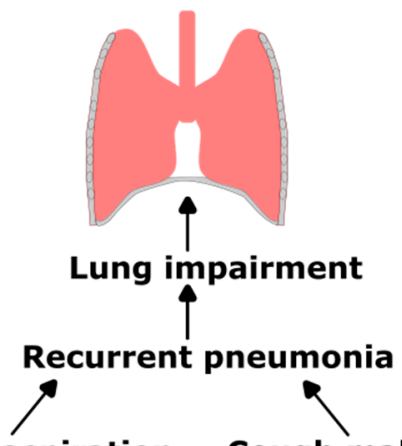

2.RESPIRATORY PUMP FAILURE

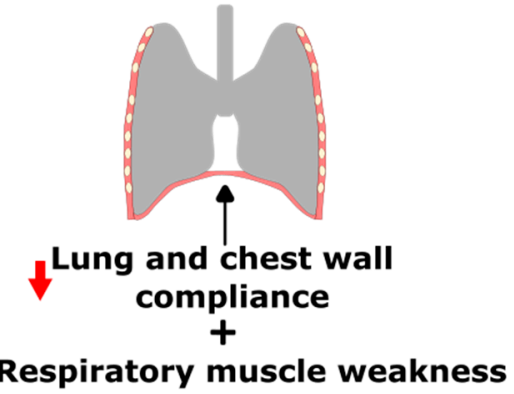

3. OBSTRUCTIVE SLEEP APNEA SYNDROM

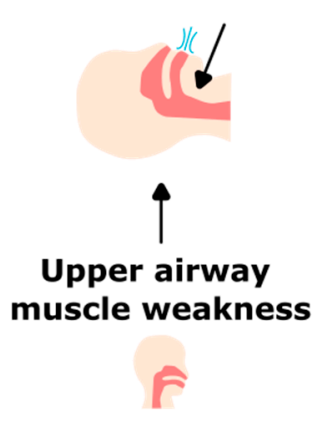

\section{Chronic aspiration Cough malfunction}

Figure 2. Diagram summarizing the three main causes of respiratory disturbances in MDs. (1) The main cause of lung failure is recurrent pneumonia usually secondary to cough inefficiency or chronic aspiration. (2) Respiratory pump failure is associated to respiratory muscle weakness (decreased pressure generating ability) combined to low respiratory system compliance (increased work of breathing). (3) Obstructive sleep apnea syndrome (OSAS) is also a common respiratory impairment, weakness of upper airway muscle enabling the inspiratory airway closure.

Respiratory failure in MDs can be classified into two forms mainly determined by the cause of the respiratory impairments: lung failure and failure of the respiratory system pump [21].

Basically, respiration is based on the exchange and renewing of gas in the lung. Preventing aspiration of fluid and secretions in the lung and maintaining airway clearance ensure the protection of these physiological processes. Most of the MDs favor these alterations leading to mucus accumulation, obstruction of the bronchi with atelectasis and lower airway infection. Recurrence of pneumonia is then the main cause of pulmonary failure in these diseases [21,22]. Cough is the corner stone of secretion clearance in the lung and upper airways. Deep inspiration, closure of the glottis, high intrathoracic pressure and expiratory flow are needed to allow its efficacy. Presence of an inspiratory muscle weakness and decreased chest wall compliance prevent patients from taking the deep breath required for an effective cough. Moreover, bulbar muscles are critical to keep the glottis closed at the beginning of the expiratory phase (allowing the huge increase in expiratory pressure). Finally, the high expiratory pressure is generated by the strength of expiratory muscle contraction that is frequently reduced in MDs. Inspiratory, expiratory and bulbar muscle weakness in MDs, therefore, prevent efficient cough and lead to secretion retention $[22,38,39]$. For instance, in DMD, the composition and volume of secretion are globally normal, but the cough effectiveness is altered in the inspiratory and expiratory cough phases due to muscular weakness. Indeed, the inspiratory phase is impaired due to diaphragmatic weakness which prevents high lung volumes to be reached. The expiratory phase is the most affected because, in addition to rib cage expiratory muscle weakness, the scoliosis adds supplemental mechanical disadvantages [40]. Expiratory muscles are also significantly weakened in some patients with FSHD, but an alteration of the ability to clear secretions from the lung has not been shown [34]. Ineffective cough also decreases the clearance of upper airways favoring benign upper-respiratory infection [41]. However, in association with a swallowing impairment due to the bulbar upper airway muscle dysfunction, the stagnation of secretion at this level leads to their chronic aspiration in the bronchi and the recurrence of pulmonary infection [21,22,42]. 
On the other side, ventilation is also frequently compromised in MDs due to respiratory pump failure. Respiratory muscle contraction generates a change in airway pressure allowing the movement of air through an open airway, increasing or decreasing lung volume depending on the activated muscles. This pressure generating ability is influenced both by the force generated by the muscle and by the elastic properties of the respiratory system. The elastic recoil of the respiratory system can be appreciated by measuring its compliance, that is its change in volume per unit change in the pressure exerted on it (and is the sum of the compliance of the chest wall and of the lung). When MDs affect respiratory muscles, their pressure generating ability decreases (usually called respiratory muscle weakness), reducing their potential to inflate or deflate the lungs. In addition, MDs also reduce the compliance of the respiratory system increasing the load against which the respiratory pump must operate [22]. Factors which increase the respiratory load involve low lung compliance and altered elastic properties of the chest wall. Causes of the reduced lung compliance are unclear. Some hypotheses have been proposed such as an incomplete maturation of lung tissue, micro- or macro-atelectasis (alveolar collapse) induced by hypoventilation, increase in alveolar surface tension and fibrosis. Concerning the increased stiffness and the decreased compliance of the chest wall, a combination of factors including muscle atrophy and osteoporosis (both consequences of inactivity), extra-articular contractures, progressive degeneration of articular cartilage and last but not least kyphoscoliosis could contribute to this phenomenon [1,21,22]. For instance, severe reductions in the chest wall compliance have been reported in patients with DMD and seem to be secondary to scoliosis. Indeed, statistically these patients lose $4 \%$ of their forced vital capacity (the maximal volume of gas that can be in- or ex-haled from the respiratory system) per year with a supplemental $4 \%$ decrease for each scoliosis severity degree reached [43]. In LAMA2 Muscular Dystrophy (MDC1A), respiratory involvement is characterized by a progressive restriction of the chest wall involving weakness of the intercostal and accessory muscles. In early stage, thoracic stiffness appears and chest wall compliance decreases [44]. Altogether, lung and chest wall compliance defect increase the muscle force needed to change lung volume. The respiratory work of breathing is therefore increased. As disease evolves, an imbalance appears between the load that has to be overcome and the capacity to overcome it, contributing to respiratory muscle fatigue and, ultimately, to respiratory failure [22].

The main consequence of respiratory failure is hypoxemia. The resulting cellular hypoxia can be divided into two forms determined by the dynamics of oxygen deprivation. First, chronic hypoxia $(\mathrm{CH})$, is mainly caused by lung failure and characterized by low oxygen saturations for prolonged periods. Second, chronic intermittent hypoxia (ChIH), usually associated to obstructive sleep apnea syndrome (OSAS) describes transient $\mathrm{O}_{2}$ reduction followed by reoxygenation periods [17,45]. Upper airway and respiratory muscle weakness are both involved in sleep-related breathing disorder (SRBD) in MDs. A high body mass index (BMI), tongue muscle weakness (especially in DM [46]) as well as craniofacial abnormalities favoring anatomical defects, can predispose patients to upper airways obstruction and OSAS during sleep. During REM (rapid eye movement) sleep and in NREM (non-rapid eye movement) deep sleep, upper airway resistance increases because the tone of skeletal muscles such as pharyngeal dilator falls. The resulting obstruction impairs airflow through the airways. The direct consequence is a desaturation leading to micro-awakening allowing reoxygenation: multiple repetitions of this sequence cause sleep fragmentation and daytime sleepiness [18,22]. On the other hand, the reduction of muscle tone also affects inspiratory muscles. While this reduction has a limited effect in normal subject, in MDs with muscle weakness and decreased compliance of the respiratory system, it induces a reduction of the tidal volume, contributing to nocturnal hypoventilation. In addition, lying in a supine posture contributes to this hypoventilation by placing the weakened muscles in an adverse mechanical condition (resulting in early symptoms of orthopnea). Four stages have been described concerning the evolution of respiratory failure in these patients: (1) SRBD, (2) hypercapnia $\left(\mathrm{PaCO}_{2}\right.$ above $\left.45 \mathrm{~mm} \mathrm{Hg}\right)$ and/or hypoxemia 
$\left(\mathrm{PaO}_{2}\right.$ lower than $60 \mathrm{mmHg}$ ) only during sleep REM phase, (3) hypercapnia and/or hypoxemia also during NREM sleep phase, and ultimately (4) diurnal chronic respiratory insufficiency [18]. According to the MD form, the onset of respiratory insufficiency can be subtle and underdiagnosed, underlining the importance of an early respiratory monitoring and management of SRDB in patients with MDs. Nocturnal oxygen desaturation is indeed associated with a worse prognosis [47]. In FSHD, respiratory involvement has first been considered as a rare manifestation of the disease associated to severity. A study reported a very low prevalence in patients with only $1 \%$ requiring home ventilatory support [48]. However, increasing evidence suggests that a nocturnal respiratory support is necessary in a larger proportion of them (around 40\%). Notably, a study involving 31 patients reported that half of them presented OSAS $[20,49,50]$. SRBDs were also reported in DM, even in the absence of typical OSAS symptoms such as excessive daytime sleepiness, highlighting the need of a polysomnographic evaluation in those patients [51].

\subsection{Muscle Ischemia}

Muscle ischemia is a condition encountered in MDs associated to vascular dysfunction and altered angiogenesis. The inadequate supply of nutrients and oxygen to the muscles is associated to a decreased removal of waste products [52]. HIF- $1 \alpha$ is stabilized during ischemia, leading to transcriptional activation of target genes that lead to vascular growth such as those encoding vascular endothelial growth factor (VEGF) and endothelial nitric oxide synthase (eNOS) [53].

Duchenne and Becker muscular dystrophy (DMD and BMD) are $\mathrm{X}$ linked disorders involving devastating muscle wasting. Both DMD and BMD are caused by mutations in the gene encoding dystrophin, a cytoplasmic cytoskeletal protein localized below the sarcolemma that it stabilizes. Dystrophin is also a scaffolding protein that acts as a mechanical link between structural and signaling proteins, forming a large and highly organized glycoprotein complex called DGC (dystrophin-associated glycoprotein complex) [54]. The muscle-specific isoform of neuronal nitric oxide synthase $(\mathrm{nNOS} \mu)$ is part of this complex. NO produced by this sarcolemmal nNOS $\mu$ normally acts as a local paracrine signal that enhances blood flow in the active muscles by decreasing sympathetic vasoconstriction. This protective mechanism called functional sympatholysis, is impaired in DMD/BMD and results in a muscle ischemia because sympathetic vasoconstriction is not inhibited [55]. Indeed, in DMD, dystrophin deficiency causes nNOS $\mu$ mislocalization, leading to the reduction of the paracrine signaling from muscle-derived NO to the microvasculature, which makes the muscle fibers more susceptible to functional ischemia during exercise. Moreover, a reduction in capillary density has been reported both in patients with DMD and in the mdx mouse model (spontaneous non-sense mutation in exon 23 of the dystrophin gene [56]), associated to an enlargement of the remaining capillaries [57,58]. Another study showed that angiogenesis was impaired in mdx mice [59]. Taken together these data suggest that DMD is associated to a defect in vascular function and angiogenesis, and that the muscles are undergoing an ischemic condition. Moreover, mdx mouse satellite cells (SC) present lower angiogenic capacity, as shown by their decreased Vegf expression. This decrease appears linked to a lower Hif-1 $\alpha$ expression in SCs [60]. Therefore, angiogenesis is currently considered as a novel therapeutic target for DMD [61,62] and administration of angiogenic factors, including VEGF and FGF, has been tested as potential treatment to enhance vascularization in ischemic diseases [63]. According to the authors, targeting HIF- $1 \alpha$, which is known to have pro-angiogenic activity, may represent a superior therapeutic approach due to the multiple pro-angiogenic pathways it controls. Indeed, blood vessels formed in pathological conditions (such as in tumor or hypoxic wounds) typically are tortuous, and leaky. This abnormal phenotype is often observed experimentally when inducing angiogenesis with a single agent, such as VEGF and as in Vegf overexpressing mice [64]. On the other hand, mice expressing constitutively active forms of Hif- $1 \alpha$ and Hif- $2 \alpha$ are also hypervascular, but present normal blood vessel phenotype [65]. 
In FSHD, a histopathological study on patient muscle biopsies suggested a decrease of capillary density [66]. Interestingly, patients affected with infantile FSHD can present exudative retinopathy due to retinal telangiectasias $[67,68]$. Moreover, as mentioned above, the pathways of HIF- $1 \alpha$ and hypoxic signaling response [69-73] as well as angiogenesis were found upregulated in FSHD muscle gene expression profiles [74]. Such deregulations may be involved in mechanisms underlying retinal blood vessel disorder in FSHD. However, the link between DUX4, the causal gene of FSHD, the microvascular abnormalities and the consequences of this capillary density defect (e.g., ischemia) remain unclear. In addition to DMD and FSHD, muscle capillary alterations were also reported in other MDs such as dystroglycanopathies. In Fukuyama type congenital MD, vascular modifications were described such as vessel basement membrane replication, blister-like swelling of endothelial cells, and platelet adhesion and aggregation in small blood vessels [75]. Capillary impairments in the eyes were also reported in another congenital MD called muscle-eye-brain [76,77].

Vascular alterations in MDs could thus be responsible for the activation of hypoxic response pathways in skeletal muscle due to lack of oxygen supply associated to ischemia. This could then lead to HIF- $1 \alpha$ stabilization in skeletal muscle whose consequences are discussed below (Section 3).

\subsection{Primary Genetic Defect}

As described above, HIF factors are stabilized under hypoxia in healthy tissues where they promote physiological adaptive mechanisms [78]. However, hypoxia and HIF-1 $\alpha$ activation were also shown involved in pathological mechanism and have been particularly studied in the cancer field. Detailed mechanisms were previously reviewed in [79]. Interestingly, an aberrant induction of HIF- $1 \alpha$ and HIF- $2 \alpha$ expression or stabilization were also reported independently from hypoxia. This condition, named "pseudohypoxia", was also mostly described in cancer, notably associated to mutations in the gene encoding pVHL [80]. Moreover, recent data highlighted such pseudo-hypoxic patterns in some MDs.

Indeed, recent studies identified the HIF- $1 \alpha$ pathway as critically disturbed in FSHD. FSHD is characterized by a progressive and often asymmetric skeletal muscle weakness. The underlying molecular mechanism is complex and involves both genetic and epigenetic components leading to the activation in skeletal muscle of DUX4 (Double Homeobox 4), a gene normally only expressed in germline and early embryogenesis. DUX4 encodes a potent transcription activator that has a causal role in FSHD pathophysiology [81-83]. Several DUX4 direct targets were identified in murine or human myoblasts but the complete DUX4 network is not completely known and mechanisms by which its stochastic expression in very few myonuclei leads to muscle weakness still have to be clarified $[84,85]$. Metaanalyses integrating gene expression data with known protein interactions identified the hypoxic response pathway as one of the main rewired networks in FSHD muscle biopsies $[69,70]$. These data confirmed previous transcriptomic studies that had described HIF- $1 \alpha$-signaling as one of the over-represented pathways among FSHD dysregulated genes [71]. Additional confirmation recently came from a genome-wide CRISPR-Cas9 screen performed to identify genes whose loss-of-function would allow survival of muscle cells expressing DUX4. Several genes of the hypoxia response pathway were found as drivers of DUX4-induced cell death [72]. Recent data mining studies have found that besides DUX4 target gene activation FSHD muscle biopsies presented a specific inhibition of the target gene signature of the muscle-specific transcription factor PAX7. Of interest, HIF- $1 \alpha$ gene expression is normally inhibited by PAX7 and PAX7 inhibition could thus contribute to HIF-1 $\alpha$ increase in FSHD muscles [70,86] (reviewed in [87]). In addition to the primary genetic defect, and a putative direct impact of DUX4 on HIF- $1 \alpha$ signaling, additional indirect activation could occur since a subgroup of patients with FSHD also present respiratory insufficiency.

HIF- $1 \alpha$ was also found deregulated in other muscular disorders such as DMD but this activation is probably an indirect consequence of other pathophysiological processes such 
as inflammation, oxidative stress, angiogenesis and muscle regeneration. These points are discussed below (Section 3).

\section{Consequences of Hypoxia and HIF-1 $\alpha$ Pathway Activation on Skeletal Muscle}

Skeletal muscles are continuously requiring oxygen supply to ensure their functions in motion, postural stabilization and breathing. They consume an important proportion of the whole-body oxygen uptake. If the local oxygen needs exceed the available supply, hypoxic stress occurs and compensatory mechanisms are activated which are collectively named hypoxia stress response pathways. The physiological activation of these pathways leads to the induction of multiple effector genes that modulate various cellular processes such as glucose metabolism and oxidative stress $[17,78,88,89]$. In skeletal muscle, hypoxia has been shown to modulate not only muscle fiber type profile but also myogenesis and regeneration [90-92].

\subsection{Impact on Myogenesis and Regeneration}

Along with their high plasticity, skeletal muscles possess a very efficient regenerative capacity. Only weeks after a complete destruction of fiber integrity, skeletal muscle structure and function can be completely restored [93]. The skeletal muscle regeneration process is carried out by several cellular and molecular events that lead to the restoration of muscle mass, muscle vascularization, and innervation, as well as the recovery of its contractile function [94]. It is important to underline that even if skeletal muscle regeneration shares some similarities with embryonic myogenesis [90,91], they differ in some aspects of their regulatory processes. Indeed, genetic requirements, e.g., their dependency on myogenic factors such as Myogenin and PAX7, are different for embryonic, fetal, post-natal and adult regenerative myogenesis [95-97]. The main mediators of muscle regeneration are myogenic progenitors called satellite cells (SCs) localized between the sarcolemma and the basal membrane of muscle fibers. Under resting conditions, SCs are quiescent and express markers such as PAX7 and MYF5. After muscle injury, SCs are activated by various signals coming from the damaged area. Activated SCs (MYF5+) then migrate toward the injury site and begin to proliferate by symmetric division. A subset of SCs (MYF5-) can undergo self-renewal to replenish the SC pool either through symmetric or asymmetric cell divisions. At this stage, these cells are called myoblasts and express the myogenic markers $P A X 7, M Y F 5$, and MYOD. After the proliferation phase, myoblasts differentiate into mature myocytes characterized by a decreased expression of $P A X 7$ and $M Y F 5$, and by an increase in MYOG (Myogenin-encoding gene) and MRF4 expression. Finally, myocytes fuse either to form multinucleated myotubes or to repair the damaged myofibers (for review see [91]) (Figure 3). In addition to the central role of SCs, muscle regeneration is a highly regulated process involving the coordinated action of additional cell types, including fibro-adipogenic progenitors, endothelial cells and macrophages [98]. 


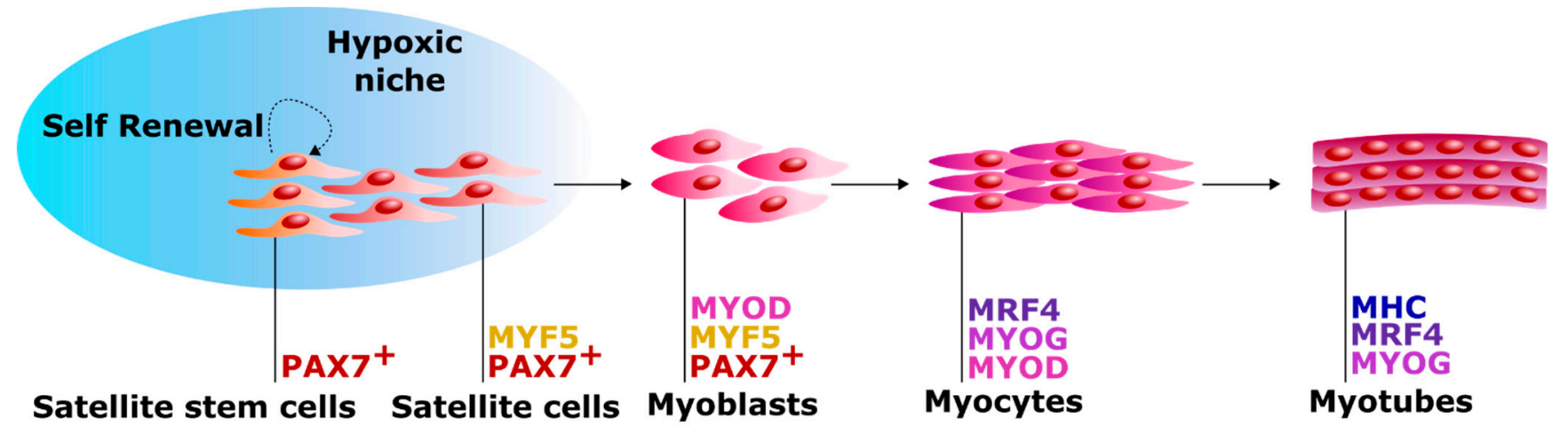

\section{CELL QUIESCENCE MAINTENANCE}

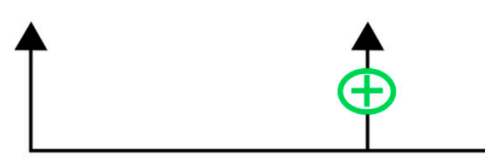

MACROPHAGE

RECRUITEMENT

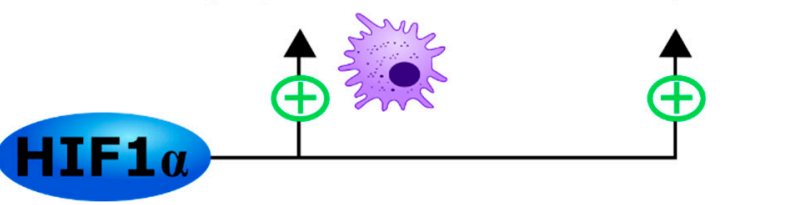

Figure 3. Myogenic differentiation. SCs are myogenic progenitors and are localized in hypoxic niches near the muscle basal membrane. Following muscle injury, quiescent SCs (PAX7+ and MYF5+/-) are activated and differentiate into myoblasts (PAX7+, MYF5+, and MYOD+). After their proliferation cycle, myoblasts differentiate into myocytes (PAX7-, MYOD+, MYOG+, and MRF4+). Finally, myocytes fuse together to form multinucleated myotubes (MYOG+, MRF4+, and MHC+). The satellite stem cell subpopulation (PAX7+ and MYF5-) can proceed to self-renewal to replenish the SC pool. HIF- $1 \alpha$ pathway activation was found critical to maintain SC quiescence [99]. It was associated to an enhanced myogenic factor activation, an increased number of PAX7+ cells, a more rapid macrophage recruitment after a myotrauma [100] and could promote myogenesis by increasing Myod expression through the WNT pathway [101].

Stem cells in both embryonic and adult organisms frequently reside in hypoxic microenvironments called hypoxic niches. A reduced oxygen level seems critical for the regulation of stem cell activity including their self-renewal, proliferation, and differentiation. Myogenic progenitor cells are also present in a hypoxic environment during embryonic development. Indeed, human development is characterized by a "physiological hypoxia" inducing a HIF-dependent transcriptional coordination of numerous genes [102]. Moreover, HIF- $1 \alpha$ is involved in mechanisms governing the quiescence of tissue-resident stem cells [103]. Since SCs are considered skeletal muscle progenitors, it is reasonable to hypothesize that the oxygen level and HIF-1 $\alpha$ pathway can affect their activity during embryonic myogenesis and adult regeneration processes [99].

In normoxic conditions, Hif- $1 \alpha$ can be detected in skeletal muscle but its protein level is dependent on the muscle fiber type [104]. A recent study in vivo showed that Phd2-deficency and the subsequent Hif-1 $\alpha$ accumulation in mice enhanced and accelerated skeletal muscle regeneration after a myotrauma [100]. In this model, the authors also described an accelerated macrophage recruitment to the injured area [100]. Myotrauma was also reported to induce a hypoxic microenvironment leading to Hif- $1 \alpha$ accumulation in myofibers and myeloid cells. In muscles of myeloid Hif- $1 \alpha \mathrm{KO}$ mice, myoblast proliferation, regenerating fiber growth and macrophage invasion were delayed after trauma [105]. In addition, Hif- $1 \alpha$ silencing in $\mathrm{C} 2 \mathrm{C} 12$ muscle cells or its chemical inhibition by echinomycin, significantly altered the differentiation process as shown by the decrease of $M y o g$ and Myosin heavy chain (MHC) expression [101]. Taken together, these studies suggest that HIF-1 $\alpha$ is necessary for myogenic differentiation under physiological conditions (Figure 3).

The influence of oxygen levels on myoblast differentiation into myotubes in vitro has been widely studied but many discrepancies exist among publications in the field. First, the effect of hypoxia on myoblast differentiation in vitro appears to be strongly dependent on the depth of hypoxia. Indeed, several publications have demonstrated that a low oxygen 
level $\left(\mathrm{O}_{2} \leq 1 \%\right)$ had harmful effects on myogenic differentiation [106-111]. For instance, the use of a chemical hypoxia-mimicking agent, namely cobalt chloride, inhibited C2C12 myoblast differentiation in a dose-dependent manner through downregulation of the myogenic factor Myogenin [112] while a moderate hypoxia could promote differentiation of $\mathrm{C} 2 \mathrm{C} 12$ muscle cells [113]. However, depending on the dose of chemical compound used to stabilize HIF- $1 \alpha$ and on the studied cell line, HIF- $1 \alpha$-independent side effects might be observed such as apoptosis, disruption of the mitochondrial transmembrane potential, upregulation of the voltage-dependent anion channels [114]. Hypoxia $\left(1 \% \mathrm{O}_{2}\right)$ promoted the differentiation of bovine primary myoblasts whereas the differentiation of C2C12 myoblasts was compromised, underlining the influence of the myogenic lineage type [115]. To summarize, the effects of hypoxia on myogenic differentiation are not completely understood, and discrepancies between studies are likely related to the different experimental parameters used such as the duration, the depth and the type of hypoxia (chemical, normo/hypobaric) as well as the myogenic lineage used (e.g., immortal cell line vs. primary cells, species (e.g., mouse vs. human), culture media) (Table 3). Finally, it is important to underline that cell cultures are usually performed in a humidified $95 \%$ air atmosphere, supplemented by $5 \% \mathrm{CO}_{2}$, providing about $20 \% \mathrm{O}_{2}$. In such hyperoxic environment, cells were shown to reset their normoxic set-point by downregulating PHD [116]. Those conditions, thus commonly considered as "normoxia" are not representative of $\mathrm{O}_{2}$ partial pressure in tissues in vivo that results from the balance between oxygen supply and consumption. In skeletal muscle, the physiological range of $\mathrm{O}_{2}$ level (termed "physioxia") is significantly lower than $20 \%\left(4 \% \mathrm{O}_{2}\right)$ [117-120]. The interpretation and translation to whole organisms of data obtained in vitro have to be made with caution by taking into account that cellular and molecular reactions to hypoxia may differ from those occurring in vivo.

Table 3. Effect of hypoxia on myogenesis in vitro.

\begin{tabular}{|c|c|c|c|c|}
\hline & & Experiments In Vitro & & \\
\hline Species & Cell Type & $\begin{array}{l}\text { Way of HIF-1 } \alpha \\
\text { Stabilization }\end{array}$ & Effect on Myogenesis & Ref. \\
\hline \multirow{4}{*}{ Mouse } & \multirow{4}{*}{$\mathrm{C} 2 \mathrm{C} 12$} & Hypoxia at $5 \% \mathrm{O}_{2}$ & No effect & \multirow{4}{*}{ [106] } \\
\hline & & Hypoxia at $2 \% \mathrm{O}_{2}$ & \multirow{3}{*}{$\begin{array}{l}\text { differentiation with } \\
\text { Myod and Myog } \\
\text { expression }\end{array}$} & \\
\hline & & Hypoxia at $0.5 \% \mathrm{O}_{2}$ & & \\
\hline & & Hypoxia at $0.01 \% \mathrm{O}_{2}$ & & \\
\hline Mouse & $\mathrm{C} 2 \mathrm{C} 12$ & Hypoxia at $0.5 \% \mathrm{O}_{2}$ & $\begin{array}{c}\searrow \text { differentiation with } \\
\searrow \text { Myod, Myog and } M h c \text { expression }\end{array}$ & [107] \\
\hline Mouse & $\mathrm{C} 2 \mathrm{C} 12$ & Hypoxia at $1 \% \mathrm{O}_{2}$ & $\begin{array}{c}\searrow \text { differentiation with } \\
\searrow M h c \text { expression dependent on } \\
\text { notch signaling }\end{array}$ & {$[108]$} \\
\hline Mouse & Primary myoblast & Hypoxia at $1 \% \mathrm{O}_{2}$ & $\begin{array}{c}\searrow \text { differentiation through } \\
\text { p53-dependent induction of Bhlhe } 40\end{array}$ & [109] \\
\hline Mouse & $\mathrm{C} 2 \mathrm{C} 12$ & Cobalt chloride & $\begin{array}{c}\searrow \text { differentiation with } \\
\searrow \text { myoblast proliferation, } \\
\searrow \text { Myog expression }\end{array}$ & {$[112]$} \\
\hline \multirow{3}{*}{ Mouse } & \multirow{3}{*}{$\mathrm{C} 2 \mathrm{C} 12$} & Hypoxia at $5 \% \mathrm{O}_{2}$ & $\begin{array}{c}\searrow \text { differentiation with } \\
\searrow \text { Myod, Myog and } M h c \text { expression }\end{array}$ & \multirow{3}{*}{ [113] } \\
\hline & & Hypoxia at $10 \% \mathrm{O}_{2}$ & \multirow{2}{*}{$\begin{array}{l}\nearrow \text { differentiation with hypertrophy } \\
\text { and } \nearrow M y o g \text { and } M h c \text { expression }\end{array}$} & \\
\hline & & Hypoxia at $15 \% \mathrm{O}_{2}$ & & \\
\hline Mouse & $\mathrm{C} 2 \mathrm{C} 12$ & Hypoxia at $1 \% \mathrm{O}_{2}$ & $\begin{array}{c}\searrow \text { differentiation with } \\
\searrow \text { Myod, Myf5, Myog and } M h c \\
\text { expression }\end{array}$ & [111] \\
\hline Rat & L6 & Hypoxia at $1 \% \mathrm{O}_{2}$ & $\begin{array}{c}\searrow \text { differentiation with } \\
\searrow \text { myoblast proliferation and } \searrow \\
\text { myogenic index }\end{array}$ & [110] \\
\hline
\end{tabular}


Table 3. Cont.

\begin{tabular}{cccc}
\hline & Experiments In Vitro & Effect on Myogenesis \\
\hline Species & Cell Type & $\begin{array}{c}\text { Way of HIF-1 } \alpha \\
\text { Stabilization }\end{array}$ & $\begin{array}{c}\searrow \text { differentiation with } \\
\text { Myod, Myf5, Myog and Mhc } \\
\text { expression }\end{array}$ \\
\hline Rat & L6E9 & Hypoxia at $1 \% \mathrm{O}_{2}$ & $\begin{array}{c}\searrow \text { differentiation with } \\
\text { myoblast proliferation and } \\
\text { myogenic index }\end{array}$ \\
\hline Human & Primary myoblasts & Hypoxia at $1 \% \mathrm{O}_{2}$ & $\begin{array}{c}\nearrow \text { differentiation with } \\
\text { SC proliferation and } \\
\text { Bovine }\end{array}$ \\
\hline SCs & Hypoxia at $1 \% \mathrm{O}_{2}$ & $\nearrow$ Myod, Myog and Mhc expression \\
\hline
\end{tabular}

$\searrow$ symbol means a decrease. $\nearrow$ symbol means an increase.

Since studies have shown that the oxygen level regulated myoblast differentiation into multinucleated myotubes in vitro $[106-113,115]$, the next question was whether hypoxia could affect skeletal muscle regeneration in vivo. In a model of soleus muscle injury induced by notexin in rats, prolonged hypobaric hypoxia ( 28 days at $10 \% \mathrm{FiO}_{2}$ (fraction of inspired oxygen)) was found to repress the early regeneration process. This repression could be linked to an attenuation of the increase of MyoD and Myog expression by hypoxia during the first week of regeneration [121]. In another study hypoxia was mimicked during skeletal muscle regeneration in rats by using dimethyloxalylglycine (DMOG) to stabilize Hif- $1 \alpha$ in injured fibers. DMOG induced a defect in the activation of the myogenic factor genes Myf-5 and Myog [122]. Altogether, those data suggested that contrary to Hif-1 stabilization, notably through Phd2 deficiency, severe and prolonged hypoxia as well as the chemical hypoxia-mimetic DMOG had a negative impact on myogenic differentiation during muscle regeneration in vivo [122-124].

Dystrophic muscles are characterized by an altered regeneration capacity along with chronic inflammation and fibrosis. Data pointing towards SC implication in MDs are accumulating, but SC contribution to muscle pathophysiology is not precisely understood [125]. Interestingly, the number of SCs was found similar in FSHD and healthy muscles [66]. Active regeneration was demonstrated in FSHD muscle biopsies by two criteria: (i) increased transcriptional expression of regeneration markers consisting of 200 human genes associated with myogenesis; (ii) presence of regenerating fibers as shown by immunolabeling for developmental myosin heavy chain [126]. However, the progressive muscle wasting observed in patients implies that this regeneration is not sufficient to prevent dystrophic changes. In another study, the proteomic profile of interstitial fluids in patient muscles showed a downregulation of structural muscle proteins and of the plasminogen pathway. Along with the inhibition of myogenic factors, this study suggested that muscle regeneration was impaired in FSHD, along with an increased fibrosis [127]. Hypoxia and HIF- $1 \alpha$ were found involved in the establishment of muscle fibrosis through crosstalk with profibrotic factors, such as Transforming Growth Factor $\beta$ (TGF- $\beta$ ) [88]. In DMD, muscles undergo repeated cycles of degeneration and impaired regeneration resulting in muscle wasting, fibrosis and fat accumulation [128]. A study focused on DMD and using mRNA profiling with large-scale data integration found that TGF- $\beta$-centered networks strongly associated with fibrosis and regeneration alteration. It also highlighted HIF- $1 \alpha$ as a notable component of this network $[129,130]$. Besides their role in muscle regeneration, SCs contribute to the revascularization of damaged muscles by secreting angiogenic factors such as VEGF. Moreover, when microvascular fragments (composed of endothelial, pericyte, and smooth muscle cells) were co-cultured with SCs, they presented stronger angiogenesis capacity than when cultured alone [131]. Another study suggested that Hepatocyte Growth Factor (HGF) played a role in SC-mediated angiogenesis. In the mdx mouse model, Hif- $1 \alpha$ and $V e g f$ expression were found decreased in proliferating SCs from dystrophic 
muscles compared to wild-type mice. This indicates that $\mathrm{mdx}$ dystrophic muscles present a decreased SC angiogenic capacity, partly through mechanisms involving a decreased $V e g f$ expression [60] and contributing to the regeneration defect in DMD. Finally, in some MDs, the pathogenic mutation resulting in myofiber wasting also directly impairs SC function and consequently alters the regeneration process. For instance, DMD muscles are characterized by degeneration/regeneration cycles leading to a muscle micro-environment presenting endomysial fibrosis, chronic inflammation and fatty infiltration. Altogether, this creates a hostile niche which could impact SC-mediated repair process [132]. In aggregate, these data demonstrate a key role for HIF- $1 \alpha$ activation in myogenesis and healthy muscle regeneration. We could therefore hypothesize that either low or excess HIF- $1 \alpha$ activation could contribute to MD muscle pathology by limiting regeneration or favoring fibrosis.

\subsection{Ultrastructural Modification}

Skeletal muscles are composed of different fiber types classified according to their metabolic and contractile properties. Slow-twitch oxidative (SO) fibers referenced as type I are rich in mitochondria, myoglobin (involved in oxygen storage) and are characterized by a high capillary density. They have a strong resistance to fatigue and rely predominantly on oxidative phosphorylation to produce their energy. Fast-twitch glycolytic (FG) fibers referenced as type II show low mitochondrial content and are more prone to fatigue. Finally, fast-twitch oxidative glycolytic (FOG) fibers are characterized by intermediate properties [133]. Over the past 25 years, modifications in the composition of myofiber types were described in conditions of pathological hypoxia, such as obstructive sleep apnea syndrome (OSAS) and respiratory failure observed in subgroups of patients with MDs [22]. A slow-to-fast fiber-type transition occurred in the lower limb muscles during chronic obstructive pulmonary disease (COPD) and in upper airway muscles during OSAS. Several factors were suggested to explain this transition.

In physioxia, Hif- $1 \alpha$ is significantly expressed and stabilized in skeletal muscle but Hif- $1 \alpha$ gene expression and protein level depend on the muscle fiber type. Indeed, higher Hif- $1 \alpha$ mRNA and protein levels were detected in predominantly glycolytic muscles, namely the gastrocnemius and quadriceps, as compared to oxidative muscles such as the soleus [104]. The authors linked these Hif- $1 \alpha$ protein variations with the myoglobin content of myofibers that is higher in oxidative muscles than in glycolytic ones. It is important to remind that skeletal muscle myoglobin acts as an intracellular oxygen buffer and constitutes an oxygen reservoir even at low $\mathrm{PO}_{2}$. Hif- $1 \alpha$ was found critical in a slow-to-fast myofiber switch, but some discrepancies remain among studies. In transgenic mice with a skeletal muscle-specific Hif- $1 \alpha$ gene inactivation, the proportion of type-IIa fibers was slightly reduced in soleus muscles as compared to the control mice and thus suggests a slightly slower fiber-type profile. Interestingly, fiber-type profile from gastrocnemius muscles did not vary between the two groups. This study also showed that endurance performance was better in Hif- $1 \alpha \mathrm{KO}$ mice than in wild-type mice. However, repeated exercise bouts induced more severe muscle damage in the $\mathrm{KO}$ mice, which consequently impaired their running performance after four consecutive days of exercise training [134]. Furthermore, the fast-to-slow fiber-type shift and the enhancement of oxidative capacity induced by long endurance training were impeded by Hif1 $\mathrm{KO}$ in skeletal muscle [135]. In contrast, Hif- $1 \alpha$ stabilized by Phd 2 conditional muscle KO caused a shift toward a slow fiber type via a calcineurin/Nfatc1 signaling pathway in the soleus and gastrocnemius muscles [136]. Accordingly, Phd $2 \mathrm{KO}$ mice had better endurance performance after training compared with control mice [137]. Interestingly Phd 2 gene inactivation could stabilize Hif-2 $\alpha$ as shown by its accumulation in Phd 2 null mouse muscles. However, this effect cannot be only attributed to the myofiber type switch. Indeed, Phd $2 \mathrm{KO}$ mice also presented an upregulation of plasmatic erythropoietin (Epo) level associated to an increased hematocrit and that likely participated to enhance aerobic capacity and endurance. Since Hif-2 $\alpha \mathrm{KO}$ leads to a slow-to fast fiber-type switch in murine soleus muscles [138], Hif- $1 \alpha$ and Hif- $2 \alpha$ could therefore have differential roles in the determination of the contractile phenotype and 
in adaptation to exercise. Although both factors share an identical core DNA binding motif, Hif- $2 \alpha$ was considered less crucial than Hif- $1 \alpha$ for acute induction of HIF target genes, but some evidence suggests that Hif- $2 \alpha$ exerts its influence in long-term exercise adaptation. Hif- $1 \alpha$ is known to be stabilized in response to an acute bout of endurance exercise but seems to be repressed by long-term endurance exercise through induction of its negative regulators [14]. This inhibition might be necessary for the switch to oxidative metabolism which is critical for endurance exercise adaptation of the skeletal muscle. In addition, Pgc1 $\alpha$ activation by endurance exercise training specifically induced Hif- $2 \alpha$ expression. This activation was dependent on estrogen-related receptor $\alpha$ [138]. The Pgc1 $\alpha / H i f-2 \alpha$ link was confirmed by the observation that Hif-2 $\alpha$ expression was decreased in the gastrocnemius of muscle-specific Pgc1 $\alpha \mathrm{KO}$ mice. Concomitantly, Hif-2 $\alpha$ induces the transcription of genes associated with slow-twitch oxidative muscle fiber phenotype and seems critical for the Pgc1 $\alpha$-induced oxidative switch in vitro [138]. Altogether, this shows that Hif- $2 \alpha$ is a downstream part of the Pgc1 $\alpha$ pathway, known to induce mitochondrial biogenesis, and acts as a key regulator of a muscle fiber-type program and the adaptive response to endurance exercise.

Fiber types are not affected in the same way in all MDs [139]. In DMD, destruction of type II muscle fibers is an early event while type I muscle fibers are lost at later stages [140]. A similar trend was observed in FSHD muscles where an early loss of type II fibers is observed together with an overall increased proportion of type I fibers [141]. In contrast, patients with DM initially present atrophy of type I fibers [142]. It remains unclear why specific fiber types are affected in certain MDs. Thus, understanding this difference of disease sensitivity may provide important insights into the pathophysiology and the development of treatments. For instance, since type II fibers appear initially affected in DMD, it was proposed to selectively promote slow muscle fiber function as a potential therapy to delay DMD progression [143]. Transgenic overexpression of $P g c 1 \alpha$ resulting in a slower fiber type phenotype [144] was shown to ameliorate muscle structural and functional defects in the mdx mouse [145]. These studies provide potential candidates that could be tested as therapeutic for the rescue of muscle dysfunction in DMD.

Altogether, available data highlight that in MDs, both the primary genetic defect and hypoxia could differently modulate myofiber type distribution, a key element of muscle function and physical properties such as fatigue resistance and exercise tolerance. A better understanding of factors and mechanisms involved in those changes remain essential to provide insights for MD patient care. In this context, the HIF-1 $\alpha$ pathway remains a central target to investigate given its role in fiber type regulation.

\subsection{Metabolic Alterations}

HIF- $1 \alpha$ is known as an important mediator of metabolic changes occurring under hypoxia. Interestingly, hypoxic response pathways are physiologically activated under particular conditions e.g., in stem cell quiescence and cell torpor (hibernating animals) [103]. In these "dormant" conditions, quiescent cells have to switch their metabolism from oxidative phosphorylation (OXPHOS) to fatty acid oxidation, anaerobic glycolysis, glutaminolysis and pentose phosphate pathway in the aim to secure a minimal energy supply and avoid metabolic dysregulation and oxidative stress $[103,146,147]$. HIF- $1 \alpha$ was reported to play a key role in those metabolic adaptations. Moreover, HIF- $1 \alpha$ is involved in metabolic changes occurring under pathological conditions, with most studied examples in the cancer field. Indeed, solid tumors are often exposed to hypoxic micro-environments. In order to support their growth and proliferation, cancer cells alter their metabolism by downregulating OXPHOS and increasing aerobic glycolysis. This metabolic shift is called "Warburg effect" and enables a rapid ATP generation to the detriment of large amounts of glucose consumption (reviewed in [148]). It also allows for $\mathrm{NAD}^{+}$production through pyruvate to lactate conversion.

Concerning skeletal muscle metabolism, we first have to mention that muscle activity is critically dependent on oxygen supply to maintain both energetic and redox status. 
Indeed, ATP hydrolysis provides an immediate energy source, but intramuscular stores of ATP are very limited and rapidly consumed. Therefore, metabolic pathways driving ATP generation are necessary to meet skeletal muscle energy requirements. Mitochondrial OXPHOS provides most ATP molecules in normoxic skeletal muscle. OXPHOS involves the reduction of oxygen to water with electron transferred from reducing equivalents (NADH and $\mathrm{FADH}_{2}$ ) that are generated in catabolic pathways such as glycolysis and $\beta$ - oxidation of fatty acids [149].

Muscle metabolic adaptations occurring upon exercise are highly dependent on training modalities, duration, frequency and intensity as reviewed in [150]. For short term energy supply, ATP is derived from phosphocreatine stock via the Lohmann reaction which takes place in the cytosol. In case of prolonged exercise, ATP will be provided by anaerobic glycolysis in the cytosol and by mitochondrial OXPHOS. Anaerobic glycolysis produces pyruvate that is then converted into lactate by lactate dehydrogenase in a reaction that provides $\mathrm{NAD}^{+}$electron acceptor needed for glycolysis.

Similarly, in experimental studies in vitro, exposure of skeletal muscle cells to hypoxic conditions leads to HIF- $1 \alpha$ activation and the subsequent up-regulation of 11 genes encoding glycolytic enzymes (aldolase A, aldolase C, enolase 1, glyceraldehyde-3-phosphate dehydrogenase, hexokinase 1, hexokinase 2, lactate dehydrogenase A, phosphofructokinase $\mathrm{L}$, phosphoglycerate kinase 1 , pyruvate kinase $\mathrm{M}$, and triosephosphate isomerase), promoting a glycolytic metabolism [151] (Figure 4). In contrast, studies on healthy individuals exposed to environmental hypoxic conditions did not measure any increased activity of most glycolytic enzymes in skeletal muscle (as reviewed in [152]). This difference could come from experimental conditions e.g., the hypoxia exposure pattern. However, besides its activity on glycolysis, HIF- $1 \alpha$ reduces OXPHOS through the induction of pyruvate dehydrogenase kinase 1 (PDK1) which decreases pyruvate entry into the mitochondrial Krebs cycle. Indeed, PDK1 inhibits by phosphorylation the E1 $\alpha$ subunit of the pyruvate dehydrogenase enzymatic complex that converts pyruvate to acetyl-coenzyme $\mathrm{A}$ and $\mathrm{CO}_{2}$ in the mitochondria. In skeletal muscle cells, Pdk1 upregulation was observed in rats exposed to $10 \% \mathrm{FiO}_{2}$ for 2 weeks [153]. Accordingly, the same upregulation was observed in human myoblasts and in mouse C2C12 cells treated with a Phd inhibitor [154]. C2C12 muscle cells treated with a Phd inhibitor presented increased production of lactate [154]. Consequently, based on cell culture studies, lactate production was expected to increase in muscle with hypoxia exposure. However, some studies did not find variation in lactate concentration and lactate-to-pyruvate ratio in muscles of healthy subjects submitted to environmental hypoxia at high altitude $[155,156]$. This observation highlights complex skeletal muscle regulations in vivo. The impact of hypoxia on carbohydrate oxidation is better documented than its consequences on lipid metabolism. In the liver, HIF- $1 \alpha$ and HIF- $2 \alpha$ are involved in hypoxia-induced lipid accumulation via a reduced fatty acid $\beta$-oxidation [157]. However, in skeletal muscle, "AltitudeOmics" studies on muscle biopsies of healthy volunteers revealed that adaptation to hypoxia was probably more complex than a simple shift from aerobic to anaerobic metabolism. According to these authors, a more efficient fatty acid $\beta$-oxidation may participate in an early phase of high-altitude hypoxia adaptation, by providing reduction equivalents to the OXPHOS electron transport chain in the absence of those derived from glycolysis [158]. Moreover, as mentioned earlier, skeletal muscle myoglobin can act as a buffer of intracellular oxygen concentration and constitutes an extra reserve of oxygen even at insufficient $\mathrm{PO}_{2}$ as encountered in hypoxic conditions. Therefore, this oxygen stock could contribute to the maintenance of ATP production by fatty acid $\beta$-oxidation in mitochondria, at least in early hypoxia adaptation. 


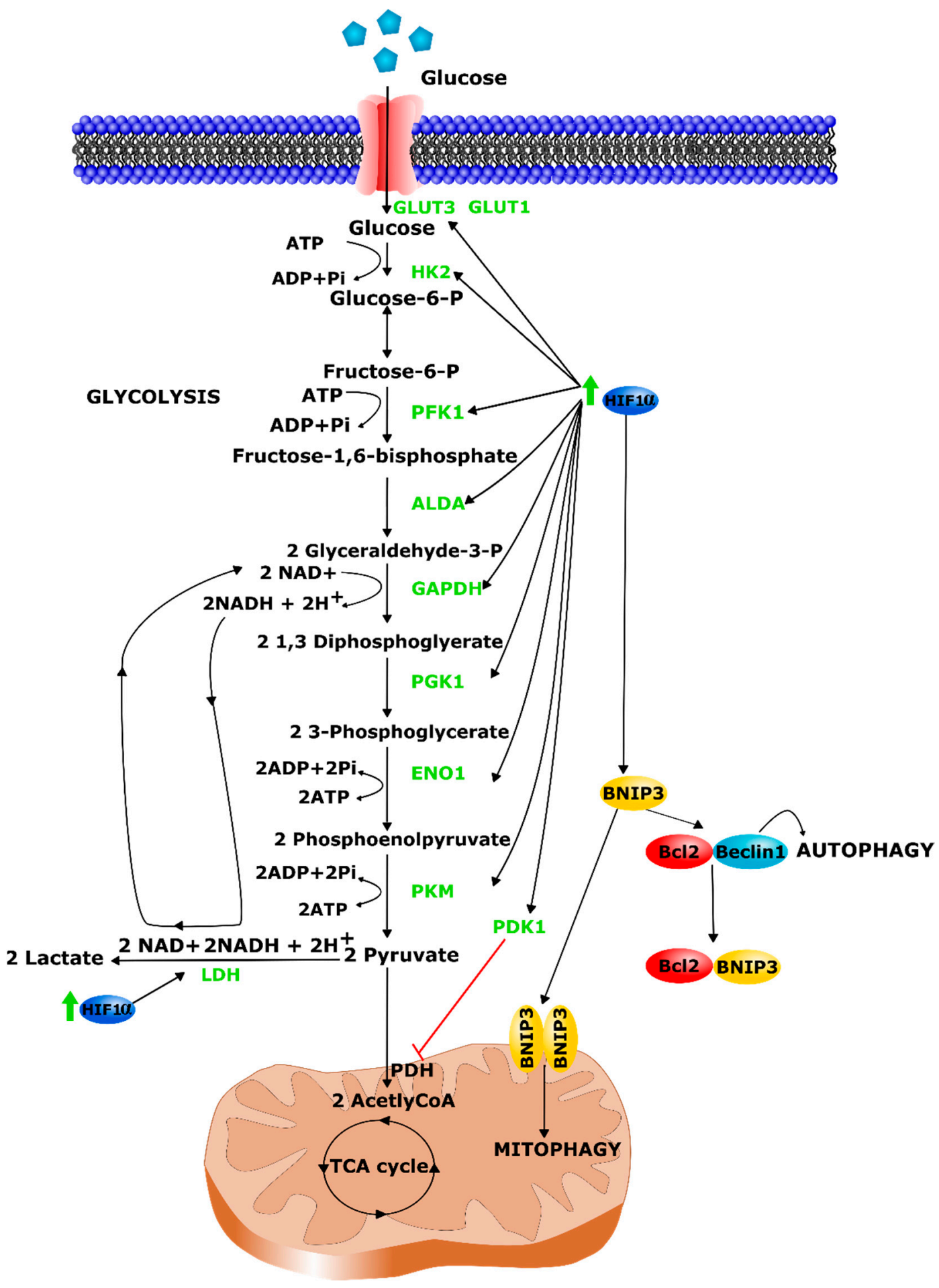

Figure 4. HIF- $1 \alpha$ control on the glycolytic switch and mitophagy. HIF- $1 \alpha$ promotes glycolytic metabolism through the induction of the expression of glycolytic transporters and enzymes (represented in green). Mechanistic aspects of the HIF-1 $\alpha$-BNIP3 induced mitophagy pathway.

Alongside with this metabolic remodeling, hypoxia exposure leads to a decrease of mitochondria content via HIF-1 $\alpha$-induced mitochondrial autophagy [159]. Autophagy is a catabolic process that eliminates or recycles defective proteins and cytoplasmic organelles to maintain homeostasis in the cell or as a mean of providing macromolecules for energy production under starvation conditions [160]. Autophagy involves the formation of autophagosomes which is initiated by the dissociation of the Beclin1/Bcl-2 complex. HIF- $1 \alpha$ 
mediates an increase in Bnip3 expression during hypoxia exposure in skeletal muscle [161-164]. Bnip3 competes with Beclin1 for Bcl-2 binding which facilitates Beclin1 release and autophagy (Figure 4) leading to decreased metabolic contribution of mitochondria and increased involvement of the glycolytic pathway to produce energy. Accordingly, mice with selective inactivation of Hif- $1 \alpha$ gene in skeletal muscle showed an increased oxidative capacity and mitochondrial content, a reduction of lactate concentration in serum and an enhanced performance during training [134].

Many MDs are associated with muscle metabolic defects. Studies have shown disturbances in glucose metabolism, including reduced glycolytic substrates, glycolytic enzyme activity such as lactate dehydrogenase, aldolase, and pyruvate kinase, and defects in insulin receptor signal transduction in DMD muscle biopsies, supporting the hypothesis of a reduced glycolytic activity [165]. Interestingly, EDL (Extensor Digitorum Longus) muscle from utrophin-dystrophin deficient dystrophic mice presented an increase in Hexokinase 1 (Hk-1) and Pyruvate kinase M2 protein levels [166]. This can be explained by the presence of more regenerating fibers with proliferating cells which mainly rely on glycolysis. Another study on golden retriever muscular dystrophy (GRMD) highlighted reduced expression of glycolytic enzymes such as 1, 6-phosphofructokinase which is regulated by Hif pathway [167]. Moreover, an mRNA profiling performed on the same model showed Glut4 downregulation but increased Hk-1 expression [168].

It is believed that the mitochondrial functional changes observed in DMD are mainly linked to dysregulation of $\mathrm{Ca}^{2+}$ homeostasis. Indeed, an early decrease in the efficiency of $\mathrm{Ca}^{2+}$ transport and accumulation in mitochondria was reported in $\mathrm{mdx}$ mice and associated with a lower rate of mitochondrial OXPHOS [121]. Moreover, evidence of insulin-resistance and other metabolic alterations such as obesity and hyperinsulinemia have been reported in DMD. Abnormal cytoplasmic aggregates of GLUT4 transporter were observed in DMD myofibers suggesting an alteration of glucose uptake in muscles [169]. In DM1, alterations in glucose metabolism, and insulin resistance were reported as an early disease manifestation. Insulin resistance is the main cause of glucose intolerance in DM1 and leads to hyperinsulinemia and later, to diabetes mellitus [170]. A recent study by NMR spectroscopy showed metabolic alterations such as glutamate/glutamine ratio or alanine decreased levels in muscle bioenergetic metabolism of patients with DMD, BMD, FSHD and limb girdle muscular dystrophy ((LGMD)-2B) both in early or acute phases of the disease [171]. Interestingly, evidence for mitochondrial dysfunction was found in FSHD muscle where impaired energy metabolism was associated with alterations in mitochondrial ultrastructure and subsarcolemmal and intramyofibrillar distribution [172]. Furthermore, a dynamic transcriptomic analysis identified that suppression of PGC1 $\alpha$, the co-factor and activator of ERR $\alpha$, a critical component of the mitochondrial biogenesis pathway, was associated to the myogenesis defect in FSHD [173]. Finally, further understanding could come from the study of mitochondrial myopathies, caused by mutations in mitochondrial DNA (mtDNA) affecting genes involved in OXPHOS such as the electron transport chain. These patients present muscular symptoms including proximal limb weakness, muscle fatigue, exercise intolerance and pain [174].

\subsection{Oxidative Stress}

Reactive oxygen species (ROS) are reactive molecules and free radicals derived from molecular oxygen such as superoxide anion $\left(\mathrm{O}_{2}{ }^{-}\right)$, hydrogen peroxide $\left(\mathrm{H}_{2} \mathrm{O}_{2}\right)$, hydroxyl radical $(\mathrm{OH})$, hydroxyl ion $\left(\mathrm{OH}^{-}\right)$. Reactive nitrogen species (RNS) are various nitric oxide-derived compounds including molecules such as nitric oxide (NO) or peroxynitrite $\left(\mathrm{ONOO}^{-}\right)$. ROS constitute a double-edged sword: depending on the magnitude, duration and cellular production site and target cells, they can either trigger beneficial or detrimental pathways $[175,176]$. Indeed, ROS are key signaling molecules in a number of physiological processes including the maintenance of muscle function and adaptation to exercise [177]. However, excessive and sustained ROS production and the imbalance between pro-oxidant and anti-oxidant pathways can cause oxidative damage to nucleic acids, proteins, and 
lipids that could initiate cell death [178]. In skeletal muscle, the ROS sources are still controversial but several reports indicate that mitochondrial electron transport is strongly involved [179-181] (Figure 5 upper part).
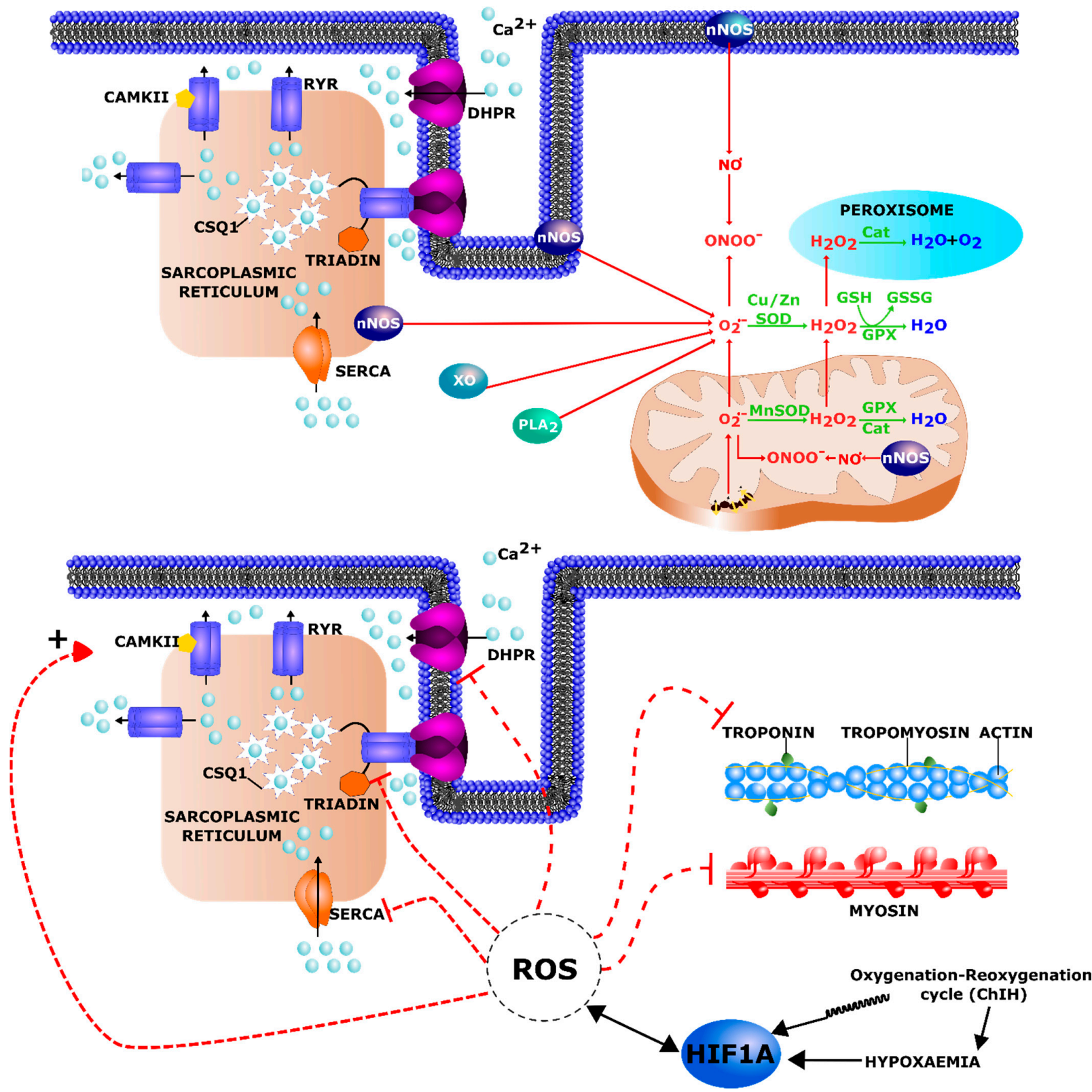

Figure 5. Upper part. Localization of the different ROS production sites and resulting ROS are linked by red arrows. Main enzymatic and non-enzymatic antioxidant defenses are represented in green. The main source of ROS is the mitochondria respiratory chain. Xanthine oxidase $(\mathrm{XO})$ and neuronal NO synthase (nNOS) play also a large part in ROS production. Phospholipase A2 ( $\left.\mathrm{PLA}_{2}\right)$ is activated by ROS and will be responsible for the hydrolysis of various products from the plasma membrane such as peroxidized fatty acids. The first antioxidant defenses are provided by superoxide dismutase (SOD) but the most important antioxidant is glutathione (GSH), a substrate of glutathione peroxidase (GPX) that neutralizes hydrogen peroxide by conversion into water. CSQ1 = Calsequestrin, the major calcium binding protein in the sarcoplasmic reticulum (SR). RyR = Ryanodine receptor, located in the SR membrane and responsible for the release of $\mathrm{Ca}^{2+}$ from the SR during excitation-contraction coupling. DHPR = dihydropyridine receptor, voltage-dependent $\mathrm{Ca}^{2+}$ channel located in T-tubule and also involved in excitation-contraction coupling. SERCA $=$ sarcoplasmic reticulum $\mathrm{Ca}^{2+}$-ATPase allowing $\mathrm{Ca}^{2+}$ active transport from the cytoplasm to the lumen of the SR during muscle relaxation. Lower part. ROS sensitive molecular targets in skeletal muscle. ROS mainly modify muscle function by altering calcium concentration regulation and by oxidizing and consequently altering contractile muscle protein structure and function. Pro-oxidant environment can lead to the activation of CAMKII $\left(\mathrm{Ca}^{2+} /\right.$ calmodulin-dependent protein kinase II) which is known to cause RyR1 phosphorylation resulting in a leakiness of $\mathrm{Ca}^{2+}$ release from the SR. 
It is known that hypoxia favors an increased ROS production both in acute [182-184] and long-term hypoxemia [185]. Deleterious ROS effects are highly dependent on the hypoxia intensity and duration $[186,187]$. Two studies $[188,189]$ have shown that acute hypoxia could lead to diaphragm muscle force reduction, as well as a decrease of both contraction and relaxation times. The use of antioxidant treatments during hypoxia rescued this loss in muscle function. This effect has been shown to be independent from the preservation of high-energy phosphates suggesting that hypoxia-induced ROS inhibits contractile function in a way that is not linked to a loss of energy status of the tissue but to the redox status of the muscle [188]. Moreover, the combination of hypoxia and exercise seems to be involved in the improvement of antioxidant capacity and might influence redox balance in a beneficial way [190].

Unlike continuous hypoxia, chronic intermittent hypoxia (ChIH) present in obstructive sleep apnea syndrome (OSAS) has pathophysiological consequences associated not only with hypoxia and hypoxia response but also with oxidative stress as a consequence of fast tissular reoxygenation. Indeed, in OSAS, each episode of intermittent hypoxia is followed by patient micro awakening and breathing, and this re-oxygenation leading to HIF- $1 \alpha$ rapid degradation (within $5 \mathrm{~min}$ ) generates ROS and oxidative stress that contribute to skeletal muscle dysfunction [191].

A previous metabonomic study performed in our laboratory has shown oxidative stress marker imbalance during ChIH exposure in mice [192]. For instance, allantoin, a urine marker of oxidative stress was significantly increased. Urinary taurine and methionine levels were decreased which indicate a higher organism consumption of these antioxidants. Several studies have demonstrated upper airway muscle dysfunction induced by ChIH [193-195]. Indeed, cycles of hypoxia-reoxygenation were shown to increase geniohyoid and sternohyoid muscle fatigue in rat models [196]. Accordingly, pro-oxidants worsen ChIH-induced respiratory muscle dysfunction [193], while the use of antioxidants improves it, underscoring the role of ROS in this phenomenon [193,195,197]. Surprisingly, only few studies focused on the impact of $\mathrm{ChIH}$ on locomotor muscles. McGuire et al. reported that chronic intermittent asphyxia led to an increased fatigue in rat $E D L$ and soleus muscles [198]. Concomitantly, another group exposed rats to chronic intermittent hypoxia-hypercapnia and found a significant downregulation in type I fibers in soleus and gastrocnemius muscle [199]. Rats exposed to ChIH also presented greater levels of mitochondrial superoxide anion that was significantly reduced by treatment with $\mathrm{N}$-acetyl cysteine (NAC) [200].

Although the genetic background of many MDs has been identified, the exact mechanism underlying skeletal muscle dysfunction often remains unclear. Oxidative stress has been deeply investigated in DMD [201] and is also obviously involved in other myopathies such as FSHD [172,202-204], SEPN1-related myopathies [205] or laminopathies [206,207]. Indeed, alterations in antioxidant responses including an increased level of oxidized glutathione and higher protein oxidation have been shown in mdx mice and in DMD muscle biopsies [208-210]. Moreover, the evaluation of antioxidant drugs in pre-clinical studies performed on mdx mice [211-214] and in clinical studies on patients with DMD [215-217] are supporting the hypothesis of a role of oxidative stress in DMD. Interestingly, a doubleblind randomized placebo-controlled phase 3 trial using the short-chain benzoquinone idebenone showed a significant reduction in the loss of respiratory function in DMD [215]. Concerning FSHD, the involvement of oxidative stress in the pathology is supported by both clinical and experimental studies. FSHD myoblasts had an increased susceptibility to oxidative stress in primary culture as shown by their significant decreased viability when exposed to the oxidative stressor paraquat as compared to control [218]. Moreover, FSHD muscle biopsies presented increased lipid peroxidation, protein carbonylation and oxidative damage (e.g., lipofuscin accumulation) as compared to control muscles [172,219]. Concerning the origin of oxidative stress in FSHD, Turki et al. showed that functional muscle alterations were associated with mitochondrial dysfunction [172]. Finally, a randomized, double-blind, placebo-controlled pilot clinical trial has shown that an oral supplementa- 
tion with an antioxidant combination to complement specific defects observed in FSHD myoblasts could moderately improve muscle function in FSHD patients [202]. Indeed, maximal voluntary contraction, and endurance limit time of the dominant and nondominant quadriceps were significantly improved in the supplemented group. This study also suggested that the effect of supplementation on physical performances might be different depending on antioxidant status and oxidative stress marker baseline of individual patients. Finally, DUX4 gene expression was found increased by oxidative stress and this phenomenon was mediated through the DNA damage response pathway highlighting a vicious circle occurring between DUX4 and oxidative stress [220]. Moreover, a recent study showed that a subset of genes was deregulated by DUX4 indirectly through oxidative stress [221]. Thus, we can hypothesize that in FSHD, oxidative stress could stabilize the HIF- $1 \alpha$ pathway which could by itself further contribute to amplify oxidative stress. However, additional studies are necessary to better understand the link between DUX4 expression, mitochondria dysfunction, oxidative stress and HIF- $1 \alpha$ activation in FSHD muscles [220]. Recent publications indicated that the target gene signature of PAX7 (an inhibitor of HIF- $1 \alpha$ gene expression) was decreased in FSHD muscle cells thus contributing to increased HIF- $1 \alpha$ protein levels [87]. Finally, it must be recalled here that OSAS occurring in a subgroup of patients with FSHD could further increase oxidative stress caused by the MD pathology.

Excessive oxidative stress can interfere with processes leading to muscular contractions at different steps (Figure 5 lower part). Indeed, excitation-contraction coupling depends on motor neuron-induced cell depolarization and the subsequent interaction between the dihydropyridine receptor (DHPR) and the ryanodine receptor (RyR1). This leads to the release of $\mathrm{Ca}^{2+}$ from the terminal cisternae of the sarcoplasmic reticulum (SR) [222]. RyR1s have been reported as channels sensitive to the redox state of muscle cells. Such alterations can induce their activation or inactivation: oxidative stress results in increased RyR1 opening leading to a $\mathrm{Ca}^{2+}$ leak [223]. Alongside with RyR destabilization, a pro-oxidant environment can lead to the activation of $\mathrm{Ca}^{2+} /$ calmodulin-dependent protein kinase II (CAMKII) which is known to cause RyR1 phosphorylation resulting in a leakiness of $\mathrm{Ca}^{2+}$ release from the SR [222]. Finally, ROS can by themselves alter myofilament structure and function. Indeed, myofilament proteins, including myosin and troponin I and C, can be oxidized and present dysfunctions after a long exposure to high ROS levels [224-227]. Interestingly, in addition to a link with oxidative stress, hypoxia was found to affect $\mathrm{Ca}^{2+}$ homeostasis. Indeed, hypoxia significantly decreased the L-type $\mathrm{Ca}^{2+}$ channel-dependent $\mathrm{Ca}^{2+}$ influx towards the cytosol and prolonged the duration of $\mathrm{Ca}^{2+}$ release from the SR through RyR channels [228]. This was confirmed in other cell types (endothelial cells and cardiomyocytes) in which chronic hypoxia increased the levels of cytosolic $\mathrm{Ca}^{2+}$ by enhancing its release from the endoplasmic reticulum $[229,230]$. Oxidative stress and hypoxia could therefore participate in MD muscle dysregulation through $\mathrm{Ca}^{2+}$ homeostasis disturbance. Moreover, increased cytosolic $\mathrm{Ca}^{2+}$ could activate calpains, a family of calcium-dependent, cysteine proteases. Indeed, mdx mice presented higher amounts and activation of ubiquitous calpains that could contribute to proteolysis and subsequent muscle wasting in DMD [231,232]. In addition, mdx mice had reduced abundance of Csq1 (calsequestrin) and Clp (calsequestrin-like protein) in the heart [233] and skeletal muscle [234], respectively. CSQ1 is the major calcium binding protein in the SR, plays an important role in calcium storage and acts as a regulator of muscle excitationcontraction coupling and stress response. Due to its lower amounts, Csq1 could thus not have a protective role against excess cytosolic $\mathrm{Ca}^{2+}$ in $\mathrm{mdx}$ mice.

Altogether, current evidence indicates that oxidative stress imbalance in skeletal muscle could contribute to pathophysiological processes in several MDs. We can hypothesize that in MDs presenting such oxidative stress imbalance (either linked to the genetic defect or as an indirect consequence of the resulting muscle pathology), the presence of an OSAS and consequently of a ChIH could exacerbate redox status disturbances and therefore muscle metabolism and dysfunction in those patients. This could be especially 
the case in patients with MDs with limited antioxidant defenses as reported in FSHD and DMD. This underlines the importance of an early screening and the monitoring of such respiratory problems.

\section{Pharmacological HIF-1 $\alpha$ Modulators in MDs}

To our knowledge, pharmacological regulators of HIF- $1 \alpha$ are not presently used in MDs. The drugs available to interfere with HIF- $1 \alpha$ expression or activity have been developed in the field of cancer and with the final purpose to induce targeted cell death. This obviously has to be avoided in the treatment of muscle disorders. A dose adaptation might allow to suppress muscle cell toxicity. However, several drugs such as those targeting the mTOR pathway seem inappropriate in MDs since they interfere with protein synthesis and would contribute to muscle atrophy [235].

Activation or inhibition of HIF pathway components should both be considered in relationship with the type of MDs. In mdx mouse, SCs presents decreased Hif- $1 \alpha$ and $V e g f$ expression that could participate in the reduced angiogenic capacity and regeneration potential. A therapy based on VEGF, an important element of the HIF- $1 \alpha$ pathway, has been proposed since alterations in the angiogenesis process have a significant impact on DMD progression. Therefore, direct delivery of VEGF has been suggested as a potential treatment option even if several limitations were highlighted by the authors (severe side effects in case of over-administration, rapid clearance resulting in a need of frequent delivery) [62].

Concerning FSHD, hypoxia response was identified as the main contributor to DUX4induced cell death [72]. In an immortalized myoblast line with inducible DUX4 expression the cellular hypoxia response could be disturbed with inhibitors of the phosphatidylinositol 3-kinase (PI3K) / Akt/mTOR or Ras/mitogen-activated protein kinase (MAPK) signaling pathways [72]. Interestingly, Losmapimod, the first compound currently in clinical trial for FSHD is a p38MAPK inhibitor, and this kinase can regulate HIF1 $\alpha$ signaling [236]. Moreover, oxidative stress was found to induce DUX4 expression [219] while the resulting oxidative stress induced additional toxic genes [221]. Agents that reduce oxidative stress allow survival of DUX4 expressing cells $[204,237,238]$ and antioxidant complementation was tested in a clinical trial for FSHD [202]: these antioxidants might also affect HIF-1 $\alpha$ which is stabilized by ROS.

\section{Conclusions}

Hypoxia and HIF- $1 \alpha$ signaling alterations clearly influence skeletal muscle structure, metabolism, regeneration and function. Both conditions occur in MDs due either to the genetic defect itself (directly or indirectly) or to a resulting respiratory insufficiency or muscle blood vessel abnormalities. Therefore, we can hypothesize that on one hand, hypoxia and MD-associated muscle disturbances themselves may have synergistic effects on key converging processes namely oxidative stress, metabolism and regeneration, initiating therefore a vicious circle whose deleterious consequences could participate in pathophysiological mechanisms underlying muscle weakness in a significant number of patients with MDs (Figure 6). On the other hand, a prolonged and aberrant HIF-1 $\alpha$ induction may also occur in MDs independently of hypoxia. Such "pseudohypoxia" could participate in muscle dysfunction in MDs through the activation of improper gene expression programs favoring e.g., cell quiescence or a metabolic shift towards lowered oxygen consumption and ATP production, such conditions being inappropriate for normal function of adult, mature skeletal muscles. 


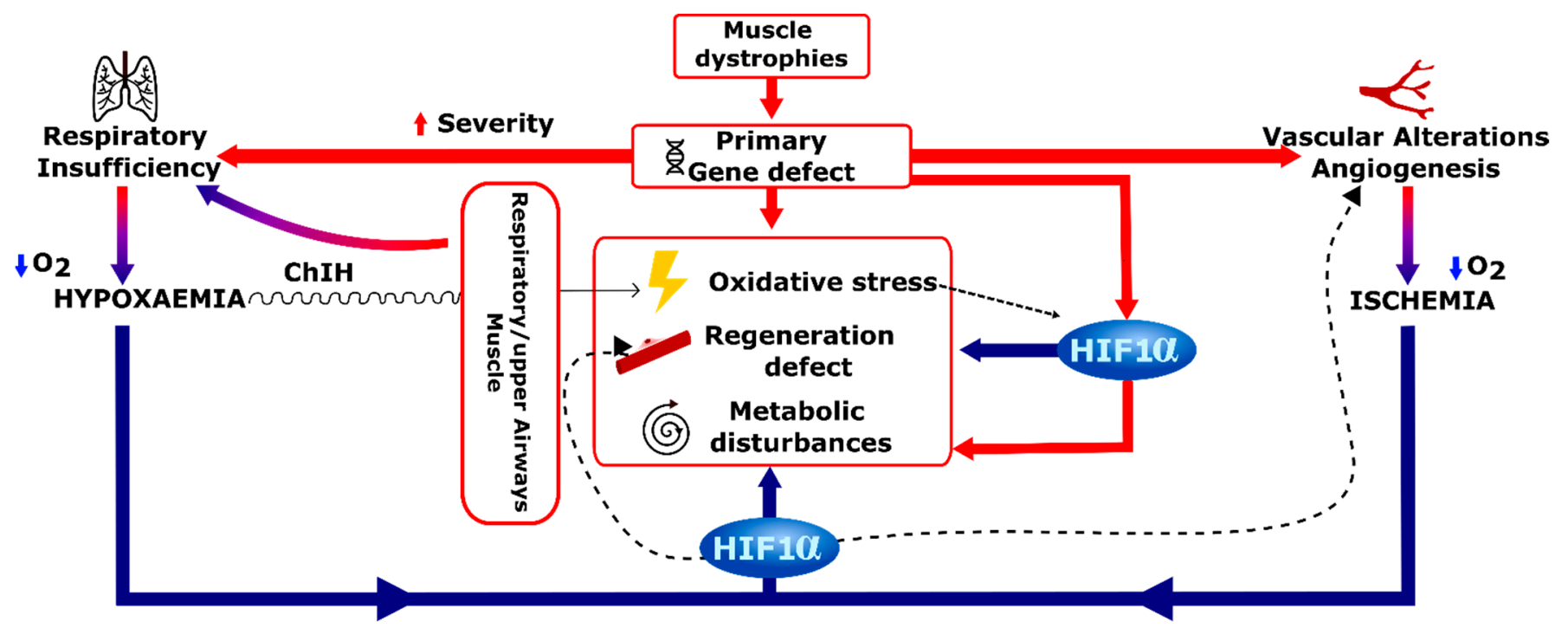

Figure 6. Overview of causes and consequences of hypoxia and HIF- $1 \alpha$ activation in the context of MDs. The activation of hypoxic response pathways could emerge as a consequence of the primary genetic defect, or via the induction of hypoxia stress response pathways as a result of an indirect mechanisms e.g., respiratory insufficiency (inducing hypoxemia) and vascular alteration (causing ischemia).

In this context, a robust monitoring of respiratory function and an early diagnosis of respiratory impairments in patients with MDs constitute key milestones. An appropriate respiratory management including non-invasive nocturnal ventilation should be considered in the presence of early nocturnal signs of hypoventilation. In the aim to provide further recommendations to improve muscle function in MDs, it remains important to increase our knowledge about the influence of hypoxia and HIF- $1 \alpha$ molecular mechanisms on MD progression. Current studies seem to point toward HIF- $1 \alpha$ as a potential therapeutic target for muscle disorders. HIF- $1 \alpha$ pharmacologic regulators and gene therapy tools currently developed in the field of cancer research may thus be useful in the development of multitherapy protocols in MDs, complementary to emerging strategies specific to individual MDs. Personalized medicine should be developed on the bases of precise criteria allowing patient clustering. In this context, a better understanding of HIF pathway components, muscle metabolic profile and redox status resulting from oxidative stress and antioxidant response in MDs will help to define new biomarkers to improve the management of co-morbidities, especially in patients with MD-associated respiratory impairments.

Author Contributions: T.-H.N. and A.T. drafted the manuscript. A.L., A.B., S.C. and A.-E.D. critically revised the manuscript. T.-H.N. designed the figures. All authors revised the final manuscript. All authors have read and agreed to the published version of the manuscript.

Funding: T.-H.N. holds a FRIA doctoral grant (FC 29703) from the National Fund for Scientific Research (F.R.S - FNRS), Belgium.

Institutional Review Board Statement: Not applicable.

Informed Consent Statement: Not applicable.

Data Availability Statement: Not applicable.

Conflicts of Interest: The authors declare no conflict of interest. 


\section{References}

1. Shahrizaila, N.; Kinnear, W.J.M.; Wills, A.J. Respiratory involvement in inherited primary muscle conditions. J. Neurol. Neurosurg. Psychiatry 2006, 77, 1108-1115. [CrossRef] [PubMed]

2. Carter, J.C.; Sheehan, D.W.; Prochoroff, A.; Birnkrant, D.J. Muscular Dystrophies. Clin. Chest Med. 2018, 39, 377-389. [CrossRef] [PubMed]

3. Mercuri, E.; Bönnemann, C.G.; Muntoni, F. Muscular dystrophies. Lancet 2019, 394, 2025-2038. [CrossRef]

4. Mensch, A.; Zierz, S. Cellular Stress in the Pathogenesis of Muscular Disorders-From Cause to Consequence. Int. J. Mol. Sci. 2020, 21, 5830. [CrossRef]

5. The Nobel Prize in Physiology or Medicine. 2019. Available online: https://www.nobelprize.org/prizes/medicine/2019 / summary / (accessed on 27 June 2021).

6. Kuiper, C.; Vissers, M.C.M. Ascorbate as a Co-Factor for Fe- and 2-Oxoglutarate Dependent Dioxygenases: Physiological Activity in Tumor Growth and Progression. Front. Oncol. 2014, 4. [CrossRef] [PubMed]

7. Safran, M.; Kaelin, W.G. HIF hydroxylation and the mammalian oxygen-sensing pathway. J. Clin. Investig. 2003, 111, 779-783. [CrossRef]

8. Schofield, C.J.; Ratcliffe, P.J. Oxygen sensing by HIF hydroxylases. Nat. Rev. Mol. Cell Biol. 2004, 5, 343-354. [CrossRef]

9. Semenza, G.L. Regulation of Mammalian O2Homeostasis by Hypoxia-Inducible Factor. Annu. Rev. Cell Dev. Biol. 1999, 15, 551-578. [CrossRef]

10. Semenza, G.L. Hypoxia-Inducible Factor 1: Control of Oxygen Homeostasis in Health and Disease. Pediatr. Res. 2001, 49, 614-617. [CrossRef]

11. Downes, N.L.; Laham-Karam, N.; Kaikkonen, M.U.; Ylä-Herttuala, S. Differential but Complementary HIF1 $\alpha$ and HIF2 $\alpha$ Transcriptional Regulation. Mol. Ther. 2018, 26, 1735-1745. [CrossRef]

12. Duan, C. Hypoxia-inducible factor 3 biology: Complexities and emerging themes. Am. J. Physiol. Physiol. 2016, 310, C260-C269. [CrossRef]

13. Morash, A.J.; Kotwica, A.O.; Murray, A.J. Tissue-specific changes in fatty acid oxidation in hypoxic heart and skeletal muscle. Am. J. Physiol. Integr. Comp. Physiol. 2013, 305, R534-R541. [CrossRef]

14. Lindholm, M.E.; Rundqvist, H. Skeletal muscle hypoxia-inducible factor-1 and exercise. Exp. Physiol. 2016, 101, 28-32. [CrossRef]

15. Gan, Z. Hypoxia in skeletal muscles: From physiology to gene expression. Musculoskelet. Regen. 2016, 2. [CrossRef]

16. Favier, F.B.; Britto, F.A.; Freyssenet, D.G.; Bigard, X.A.; Benoit, H. HIF-1-driven skeletal muscle adaptations to chronic hypoxia: Molecular insights into muscle physiology. Cell. Mol. Life Sci. 2015, 72, 4681-4696. [CrossRef] [PubMed]

17. Clanton, T.L.; Klawitter, P.F. Invited Review: Adaptive responses of skeletal muscle to intermittent hypoxia: The known and the unknown. J. Appl. Physiol. 2001, 90, 2476-2487. [CrossRef] [PubMed]

18. Mauro, M.A.L.; D’Angelo, M.G.; Aliverti, A. Sleep Disordered Breathing in Duchenne Muscular Dystrophy. Curr. Neurol. Neurosci. Rep. 2017, 17, 44. [CrossRef]

19. Hoque, R. Sleep-Disordered Breathing in Duchenne Muscular Dystrophy: An Assessment of the Literature. J. Clin. Sleep Med. 2016, 12, 905-911. [CrossRef] [PubMed]

20. Runte, M.; Spiesshoefer, J.; Heidbreder, A.; Dreher, M.; Young, P.; Brix, T.; Boentert, M. Sleep-related breathing disorders in facioscapulohumeral dystrophy. Sleep Breath. 2019, 23, 899-906. [CrossRef] [PubMed]

21. Allen, J. Pulmonary complications of neuromuscular disease: A Respiratory mechanics perspective. Paediatr. Respir. Rev. 2010, 11, 18-23. [CrossRef]

22. Lo Mauro, A.; Aliverti, A. Physiology of respiratory disturbances in muscular dystrophies. Breathe 2016, 12, 318-327. [CrossRef] [PubMed]

23. Pane, M.; Messina, S.; Vasco, G.; Foley, A.R.; Morandi, L.; Pegoraro, E.; Mongini, T.; D'Amico, A.; Bianco, F.; Lombardo, M.E.; et al. Respiratory and cardiac function in congenital muscular dystrophies with alpha dystroglycan deficiency. Neuromuscul. Disord. 2012, 22, 685-689. [CrossRef]

24. Johnson, K.; Bertoli, M.; Phillips, L.; Töpf, A.; Van den Bergh, P.; Vissing, J.; Witting, N.; Nafissi, S.; Jamal-Omidi, S.; Łusakowska, A.; et al. Detection of variants in dystroglycanopathy-associated genes through the application of targeted whole-exome sequencing analysis to a large cohort of patients with unexplained limb-girdle muscle weakness. Skelet. Muscle $2018,8,23$. [CrossRef]

25. Jimenez-Mallebrera, C.; Brown, S.C.; Sewry, C.A.; Muntoni, F. Congenital muscular dystrophy: Molecular and cellular aspects. Cell. Mol. Life Sci. 2005, 62, 809-823. [CrossRef] [PubMed]

26. Collins, J.; Van Dyke, R.; Fenchel, M.; McCallum, M.; Völker, S.; Foley, A.R.; Muntoni, F.; Stehling, F.; Schara, U.; Rutkowski, A.; et al. S.P.23 Percent predicted forced vital capacity is a viable outcome measure in Laminin alpha 2-Deficient congenital muscular dystrophy. Neuromuscul. Disord. 2012, 22, 893-894. [CrossRef]

27. Villar-Quiles, R.N.; Von Der Hagen, M.; Métay, C.; Gonzalez, V.; Donkervoort, S.; Bertini, E.; Castiglioni, C.; Chaigne, D.; Colomer, J.; Cuadrado, M.L.; et al. The clinical, histological, and genotypic spectrum of SEPN1-related myopathy: A case series. Neurology 2020, 95, e1512-e1527. [CrossRef]

28. Caggiano, S.; Khirani, S.; Dabaj, I.; Cavassa, E.; Amaddeo, A.; Arroyo, J.O.; Desguerre, I.; Richard, P.; Cutrera, R.; Ferreiro, A.; et al. Diaphragmatic dysfunction in SEPN1-related myopathy. Neuromuscul. Disord. 2017, 27, 747-755. [CrossRef] [PubMed] 
29. Yonekawa, T.; Komaki, H.; Okada, M.; Hayashi, Y.K.; Nonaka, I.; Sugai, K.; Sasaki, M.; Nishino, I. Rapidly progressive scoliosis and respiratory deterioration in Ullrich congenital muscular dystrophy. J. Neurol. Neurosurg. Psychiatry 2013, 84, 982-988. [CrossRef]

30. LoMauro, A.; Romei, M.; Gandossini, S.; Pascuzzo, R.; Vantini, S.; D'Angelo, M.G.; Aliverti, A. Evolution of respiratory function in Duchenne muscular dystrophy from childhood to adulthood. Eur. Respir. J. 2018, 51. [CrossRef]

31. Taylor, J.; Sewry, C.A.; Dubowitz, V.; Muntoni, F. Early onset, autosomal recessive muscular dystrophy with Emergy-Dreifuss phenotype and normal emerin expression. Neurology 1998, 51, 1116-1120. [CrossRef]

32. Santos, D.B.; Boussaid, G.; Stojkovic, T.; Orlikowski, D.; Letilly, N.; Béhin, A.; Butel, S.; Lofaso, F.; Prigent, H. Respiratory muscle dysfunction in facioscapulohumeral muscular dystrophy. Neuromuscul. Disord. 2015, 25, 632-639. [CrossRef]

33. Moreira, S.; Wood, L.; Smith, D.; Marini-Bettolo, C.; Guglieri, M.; McMacken, G.; Bailey, G.; Mayhew, A.; Muni-Lofra, R.; Eglon, G.; et al. Respiratory involvement in ambulant and non-ambulant patients with facioscapulohumeral muscular dystrophy. $J$. Neurol. 2017, 264, 1271-1280. [CrossRef]

34. Henke, C.; Spiesshoefer, J.; Kabitz, H.-J.; Herkenrath, S.; Randerath, W.; Brix, T.; Görlich, D.; Young, P.; Boentert, M. Respiratory muscle weakness in facioscapulohumeral muscular dystrophy. Muscle Nerve 2019, 60, 679-686. [CrossRef]

35. D'Angelo, M.G.; Romei, M.; Lo Mauro, A.; Marchi, E.; Gandossini, S.; Bonato, S.; Comi, G.P.; Magri, F.; Turconi, A.C.; Pedotti, A.; et al. Respiratory pattern in an adult population of dystrophic patients. J. Neurol. Sci. 2011, 306, 54-61. [CrossRef]

36. Henke, C.; Spiesshoefer, J.; Kabitz, H.-J.; Herkenrath, S.; Randerath, W.; Brix, T.; Görlich, D.; Young, P.; Boentert, M. Characteristics of respiratory muscle involvement in myotonic dystrophy type. Neuromuscul. Disord. 2020, 30, 17-27. [CrossRef]

37. Hawkins, A.M.; Hawkins, C.L.; Razak, K.A.; Khoo, T.K.; Tran, K.; Jackson, R.V. Respiratory dysfunction in myotonic dystrophy type 1: A systematic review. Neuromuscul. Disord. 2019, 29, 198-212. [CrossRef] [PubMed]

38. Perrin, C.; Unterborn, J.N.; Ambrosio, C.D.; Hill, N.S. Pulmonary complications of chronic neuromuscular diseases and their management. Muscle Nerve 2004, 29, 5-27. [CrossRef] [PubMed]

39. Aliverti, A.; Lo Mauro, A.; D'Angelo, M.G. Assessment and management of respiratory function in patients with Duchenne muscular dystrophy: Current and emerging options. Ther. Clin. Risk Manag. 2015, 11, 1475-1488. [CrossRef]

40. Kravitz, R.M. Airway Clearance in Duchenne Muscular Dystrophy. Pediatrics 2009, 123, S231-S235. [CrossRef] [PubMed]

41. Bach, J.R.; Rajaraman, R.; Ballanger, F.; Tzeng, A.C.; Ishikawa, Y.; Kulessa, R.; Bansal, T. Neuromuscular Ventilatory Insufficiency Effect of Home Mechanical Ventilator Use v Oxygen Therapy on Pneumonia and Hospitalization Rates. Am. J. Phys. Med. Rehabil. 1998, 77, 8-19. [CrossRef] [PubMed]

42. Eikermann, M.; Vogt, F.M.; Herbstreit, F.; Vahid-Dastgerdi, M.; Zenge, M.O.; Ochterbeck, C.; De Greiff, A.; Peters, J. The Predisposition to Inspiratory Upper Airway Collapse during Partial Neuromuscular Blockade. Am. J. Respir. Crit. Care Med. 2007, 175, 9-15. [CrossRef]

43. Kurz, L.T.; Mubarak, S.J.; Schultz, P.; Park, S.M.; Leach, J. Correlation of Scoliosis and Pulmonary Function in Duchenne Muscular Dystrophy. J. Pediatr. Orthop. 1983, 3, 347-353. [CrossRef]

44. Oliveira, J.; Parente Freixo, J.; Santos, M.; Coelho, T. LAMA2 Muscular Dystrophy. In GeneReviews ${ }^{\circledR}$; Adam, M.P., Ardinger, H.H., Pagon, R.A., Wallace, S.E., Bean, L.J., Mirzaa, G., Amemiya, A., Eds.; University of Washington: Seattle, WA, USA, 1993.

45. Saxena, K.; Jolly, M.K. Acute vs. Chronic vs. Cyclic Hypoxia: Their Differential Dynamics, Molecular Mechanisms, and Effects on Tumor Progression. Biomolecules 2019, 9, 339. [CrossRef] [PubMed]

46. Irfan, M.; Selim, B.; Rabinstein, A.A.; St. Louis, E.K. Neuromuscular Disorders and Sleep in Critically Ill Patients. Crit. Care Clin. 2015, 31, 533-550. [CrossRef] [PubMed]

47. Phillips, M.F.; Smith, P.E.; Carroll, N.; Edwards, R.H.; Calverley, P.M. Nocturnal Oxygenation and Prognosis in Duchenne Muscular Dystrophy. Am. J. Respir. Crit. Care Med. 1999, 160, 198-202. [CrossRef] [PubMed]

48. Wohlgemuth, M.; Van Der Kooi, E.L.; Van Kesteren, R.G.; van der Maarel, S.; Padberg, G.W. Ventilatory support in facioscapulohumeral muscular dystrophy. Neurology 2004, 63, 176-178. [CrossRef]

49. Della Marca, G.; Pantanali, F.; Frusciante, R.; Scarano, E.; Cianfoni, A.; Calò, L.; Dittoni, S.; Vollono, C.; Losurdo, A.; Testani, E.; et al. Cephalometric findings in facioscapulohumeral muscular dystrophy patients with obstructive sleep apneas. Sleep Breath. 2010, 15, 99-106. [CrossRef]

50. Della Marca, G.; Frusciante, R.; Dittoni, S.; Vollono, C.; Buccarella, C.; Iannaccone, E.; Rossi, M.; Scarano, E.; Pirronti, T.; Cianfoni, A.; et al. Sleep disordered breathing in facioscapulohumeral muscular dystrophy. J. Neurol. Sci. 2009, 285, 54-58. [CrossRef]

51. Kiyan, E.; Okumus, G.; Cuhadaroglu, C.; Deymeer, F. Sleep apnea in adult myotonic dystrophy patients who have no excessive daytime sleepiness. Sleep Breath. 2009, 14, 19-24. [CrossRef]

52. Tennant, D.; Howell, N.J. The role of HIFs in ischemia-reperfusion injury. Hypoxia 2014, 2, 107-115. [CrossRef]

53. Milkiewicz, M.; Pugh, C.W.; Egginton, S. Inhibition of endogenous HIF inactivation induces angiogenesis in ischaemic skeletal muscles of mice. J. Physiol. 2004, 560, 21-26. [CrossRef] [PubMed]

54. Yiu, E.M.; Kornberg, A.J. Duchenne muscular dystrophy. J. Paediatr. Child Health 2015, 51, 759-764. [CrossRef]

55. Thomas, G.D. Functional muscle ischemia in Duchenne and Becker muscular dystrophy. Front. Physiol. 2013, 4, 381. [CrossRef] [PubMed]

56. Sicinski, P.; Geng, Y.; Ryder-Cook, A.S.; Barnard, E.A.; Darlison, M.G.; Barnard, P.J. The molecular basis of muscular dystrophy in the mdx mouse: A point mutation. Science 1989, 244, 1578-1580. [CrossRef] [PubMed] 
57. Buckley, A.F.; Bossen, E.H. Skeletal Muscle Microvasculature in the Diagnosis of Neuromuscular Disease. J. Neuropathol. Exp. Neurol. 2013, 72, 906-918. [CrossRef] [PubMed]

58. Loufrani, L.; Dubroca, C.; You, D.; Li, Z.; Levy, B.; Paulin, D.; Henrion, D. Absence of Dystrophin in Mice Reduces NO-Dependent Vascular Function and Vascular Density: Total Recovery After a Treatment with the Aminoglycoside Gentamicin. Arter. Thromb. Vasc. Biol. 2004, 24, 671-676. [CrossRef]

59. Palladino, M.; Gatto, I.; Neri, V.; Straino, S.; Smith, R.C.; Silver, M.; Gaetani, E.; Marcantoni, M.; Giarretta, I.; Stigliano, E.; et al. Angiogenic Impairment of the Vascular Endothelium. Arter. Thromb. Vasc. Biol. 2013, 33, 2867-2876. [CrossRef]

60. Rhoads, R.P.; Flann, K.L.; Cardinal, T.R.; Rathbone, C.R.; Liu, X.; Allen, R.E. Satellite cells isolated from aged or dystrophic muscle exhibit a reduced capacity to promote angiogenesis In Vitro. Biochem. Biophys. Res. Commun. 2013, 440, 399-404. [CrossRef]

61. Shimizu-Motohashi, Y.; Asakura, A. Angiogenesis as a novel therapeutic strategy for Duchenne muscular dystrophy through decreased ischemia and increased satellite cells. Front. Physiol. 2014, 5. [CrossRef]

62. Podkalicka, P.; Mucha, O.; Dulak, J.; Loboda, A. Targeting angiogenesis in Duchenne muscular dystrophy. Cell. Mol. Life Sci. 2019, 76, 1507-1528. [CrossRef]

63. Krock, B.L.; Skuli, N.; Simon, M.C. Hypoxia-Induced Angiogenesis: Good and Evil. Genes Cancer 2011, 2, 1117-1133. [CrossRef]

64. Thurston, G. Complementary actions of VEGF and Angiopoietin-1 on blood vessel growth and leakage. J. Anat. 2002, 200, 575-580. [CrossRef]

65. Elson, D.A.; Thurston, G.; Huang, L.E.; Ginzinger, D.G.; McDonald, D.M.; Johnson, R.S.; Arbeit, J.M. Induction of hypervascularity without leakage or inflammation in transgenic mice overexpressing hypoxia-inducible factor-1alpha. Genes Dev. 2001, 15, 25202532. [CrossRef] [PubMed]

66. Statland, J.M.; Odrzywolski, K.J.; Shah, B.; Henderson, D.J.; Fricke, A.F.; van der Maarel, S.M.; Tapscott, S.J.; Tawil, R. Immunohistochemical Characterization of Facioscapulohumeral Muscular Dystrophy Muscle Biopsies. J. Neuromuscul. Dis. 2015, 2, 291-299. [CrossRef] [PubMed]

67. Shields, C.L.; Zahler, J.; Falk, N.; Furuta, M.; Eagle, R.C.; Espinosa, L.E.B.; Fischer, P.R.; Shields, J.A. Neovascular Glaucoma From Advanced Coats Disease as the Initial Manifestation of Facioscapulohumeral Dystrophy in a 2-Year-Old Child. Arch. Ophthalmol. 2007, 125, 840-842. [CrossRef] [PubMed]

68. Goselink, R.J.M.; Schreur, V.; Van Kernebeek, C.R.; Padberg, G.W.; Van Der Maarel, S.M.; Van Engelen, B.G.M.; Erasmus, C.E.; Theelen, T. Ophthalmological findings in facioscapulohumeral dystrophy. Brain Commun. 2019, 1, 1. [CrossRef] [PubMed]

69. Banerji, C.R.S.; Knopp, P.; Moyle, L.A.; Severini, S.; Orrell, R.W.; Teschendorff, A.E.; Zammit, P.S. $\beta$-catenin is central to DUX4 -driven network rewiring in facioscapulohumeral muscular dystrophy. J. R. Soc. Interface 2015, 12, 20140797. [CrossRef] [PubMed]

70. Banerji, C.R.S.; Panamarova, M.; Hebaishi, H.; White, R.B.; Relaix, F.; Severini, S.; Zammit, P.S. PAX7 target genes are globally repressed in facioscapulohumeral muscular dystrophy skeletal muscle. Nat. Commun. 2017, 8, 1-13. [CrossRef] [PubMed]

71. Tsumagari, K.; Chang, S.-C.; Lacey, M.; Baribault, C.; Chittur, S.V.; Sowden, J.; Tawil, R.; Crawford, G.E.; Ehrlich, M. Gene expression during normal and FSHD myogenesis. BMC Med. Genom. 2011, 4, 67. [CrossRef]

72. Lek, A.; Zhang, Y.; Woodman, K.G.; Huang, S.; DeSimone, A.M.; Cohen, J.; Ho, V.; Conner, J.; Mead, L.; Kodani, A.; et al. Applying genome-wide CRISPR-Cas9 screens for therapeutic discovery in facioscapulohumeral muscular dystrophy. Sci. Transl. Med. 2020, 12. [CrossRef]

73. Geng, L.N.; Yao, Z.; Snider, L.; Fong, A.P.; Cech, J.N.; Young, J.M.; van der Maarel, S.; Ruzzo, W.L.; Gentleman, R.C.; Tawil, R.; et al. DUX4 Activates Germline Genes, Retroelements, and Immune Mediators: Implications for Facioscapulohumeral Dystrophy. Dev. Cell 2012, 22, 38-51. [CrossRef] [PubMed]

74. Osborne, R.J.; Welle, S.; Venance, S.L.; Thornton, C.A.; Tawil, R. Expression profile of FSHD supports a link between retinal vasculopathy and muscular dystrophy. Neurology 2006, 68, 569-577. [CrossRef]

75. Sugino, S.; Miyatake, M.; Ohtani, Y.; Yoshioka, K.; Miike, T.; Uchino, M. Vascular alterations in Fukuyama type congenital muscular dystrophy. Brain Dev. 1991, 13, 77-81. [CrossRef]

76. Zervos, A.; Hunt, K.E.; Tong, H.-Q.; Avallone, J.; Morales, J.; Friedman, N.; Cohen, B.H.; Clark, B.; Guo, S.; Gazda, H.; et al. Clinical, genetic and histopathologic findings in two siblings with muscle-eye-brain disease. Eur. J. Ophthalmol. 2002, 12, $253-261$. [CrossRef] [PubMed]

77. Hoang, Q.V.; Blair, M.P.; Rahmani, B.; Galasso, J.M.; Shapiro, M.J. Multiple Retinal Holes and Peripheral Nonperfusion in Muscle-Eye-Brain Disease. Arch. Ophthalmol. 2011, 129, 373-375. [CrossRef]

78. Koh, M.Y.; Spivak-Kroizman, T.R.; Powis, G. HIF-1 regulation: Not so easy come, easy go. Trends Biochem. Sci. 2008, 33, 526-534. [CrossRef]

79. Muz, B.; de la Puente, P.; Azab, F.; Azab, A.K. The role of hypoxia in cancer progression, angiogenesis, metastasis, and resistance to therapy. Hypoxia 2015, 3, 83-92. [CrossRef]

80. Macklin, P.S.; Yamamoto, A.; Browning, L.; Hofer, M.; Adam, J.; Pugh, C.W. Recent advances in the biology of tumour hypoxia with relevance to diagnostic practice and tissue-based research. J. Pathol. 2020, 250, 593-611. [CrossRef]

81. Gabriëls, J.; Beckers, M.-C.; Ding, H.; De Vriese, A.; Plaisance, S.M.; van der Maarel, S.; Padberg, G.W.; Frants, R.R.; Hewitt, J.E.; Collen, D.; et al. Nucleotide sequence of the partially deleted D4Z4 locus in a patient with FSHD identifies a putative gene within each $3.3 \mathrm{~kb}$ element. Gene 1999, 236, 25-32. [CrossRef] 
82. Dixit, M.; Ansseau, E.; Tassin, A.; Winokur, S.; Shi, R.; Qian, H.; Sauvage, S.; Matteotti, C.; van Acker, A.M.; Leo, O.; et al. DUX4, a candidate gene of facioscapulohumeral muscular dystrophy, encodes a transcriptional activator of PITX1. Proc. Natl. Acad. Sci. USA 2007, 104, 18157-18162. [CrossRef]

83. Tassin, A.; Laoudj-Chenivesse, D.; Vanderplanck, C.; Barro, M.; Charron, S.; Ansseau, E.; Chen, Y.-W.; Mercier, J.; Coppée, F.; Belayew, A. DUX4 expression in FSHD muscle cells: How could such a rare protein cause a myopathy? J. Cell. Mol. Med. 2012, 17, 76-89. [CrossRef] [PubMed]

84. Lim, K.R.Q.; Nguyen, Q.; Yokota, T. DUX4 Signalling in the Pathogenesis of Facioscapulohumeral Muscular Dystrophy. Int. J. Mol. Sci. 2020, 21, 729. [CrossRef]

85. Wagner, K.R. Facioscapulohumeral Muscular Dystrophies. Contin. Lifelong Learn. Neurol. 2019, 25, 1662-1681. [CrossRef]

86. Banerji, C.R.S. PAX7 target gene repression associates with FSHD progression and pathology over 1 year. Hum. Mol. Genet. 2020, 29, 2124-2133. [CrossRef]

87. Banerji, C.R.S.; Zammit, P.S. Pathomechanisms and biomarkers in facioscapulohumeral muscular dystrophy: Roles of DUX4 and PAX7. EMBO Mol. Med. 2021, e13695. [CrossRef]

88. Valle-Tenney, R.; Rebolledo, D.; Acuña, M.J.; Brandan, E. HIF-hypoxia signaling in skeletal muscle physiology and fibrosis. J. Cell Commun. Signal. 2020, 14, 147-158. [CrossRef]

89. Majmundar, A.J.; Wong, W.J.; Simon, M.C. Hypoxia-Inducible Factors and the Response to Hypoxic Stress. Mol. Cell 2010, 40, 294-309. [CrossRef]

90. Chaillou, T.; Lanner, J.T. Regulation of myogenesis and skeletal muscle regeneration: Effects of oxygen levels on satellite cell activity. FASEB J. 2016, 30, 3929-3941. [CrossRef]

91. Dumont, N.A.; Bentzinger, C.F.; Sincennes, M.-C.; Rudnicki, M.A. Satellite Cells and Skeletal Muscle Regeneration. In Comprehensive Physiology; John Wiley \& Sons: Hoboken, NJ, USA, 2015; pp. 1027-1059. ISBN 978-0-470-65071-4.

92. Chaillou, T. Skeletal Muscle Fiber Type in Hypoxia: Adaptation to High-Altitude Exposure and Under Conditions of Pathological Hypoxia. Front. Physiol. 2018, 9. [CrossRef]

93. Bentzinger, C.F.; Wang, Y.X.; Dumont, N.A.; Rudnicki, M.A. Cellular dynamics in the muscle satellite cell niche. EMBO Rep. 2013, 14, 1062-1072. [CrossRef]

94. Chargé, S.B.P.; Rudnicki, M.A. Cellular and Molecular Regulation of Muscle Regeneration. Physiol. Rev. 2004, 84, 209-238. [CrossRef]

95. Meadows, E.; Cho, J.-H.; Flynn, J.M.; Klein, W.H. Myogenin regulates a distinct genetic program in adult muscle stem cells. Dev. Biol. 2008, 322, 406-414. [CrossRef]

96. Hasty, P.; Bradley, A.; Morris, J.H.; Edmondson, D.G.; Venuti, J.M.; Olson, E.N.; Klein, W.H. Muscle deficiency and neonatal death in mice with a targeted mutation in the myogenin gene. Nat. Cell Biol. 1993, 364, 501-506. [CrossRef]

97. Lepper, C.; Conway, S.J.; Fan, C.-M. Adult satellite cells and embryonic muscle progenitors have distinct genetic requirements. Nat. Cell Biol. 2009, 460, 627-631. [CrossRef]

98. Dort, J.; Fabre, P.; Molina, T.; Dumont, N.A. Macrophages Are Key Regulators of Stem Cells during Skeletal Muscle Regeneration and Diseases. Stem Cells Int. 2019, 2019, 4761427. [CrossRef]

99. Yang, X.; Yang, S.; Wang, C.; Kuang, S. The hypoxia-inducible factors HIF1 $\alpha$ and HIF2 $\alpha$ are dispensable for embryonic muscle development but essential for postnatal muscle regeneration. J. Biol. Chem. 2017, 292, 5981-5991. [CrossRef]

100. Settelmeier, S.; Schreiber, T.; Mäki, J.; Byts, N.; Koivunen, P.; Myllyharju, J.; Fandrey, J.; Winning, S. Prolyl hydroxylase domain 2 reduction enhances skeletal muscle tissue regeneration after soft tissue trauma in mice. PLoS ONE 2020, 15. [CrossRef]

101. Cirillo, F.; Resmini, G.; Ghiroldi, A.; Piccoli, M.; Bergante, S.; Tettamanti, G.; Anastasia, L. Activation of the hypoxia-inducible factor 1a promotes myogenesis through the noncanonical Wnt pathway, leading to hypertrophic myotubes. FASEB J. 2017, 31, 2146-2156. [CrossRef]

102. Park, A.M.; Sanders, T.A.; Maltepe, E. Hypoxia-inducible factor (HIF) and HIF-stabilizing agents in neonatal care. Semin. Fetal Neonatal Med. 2010, 15, 196-202. [CrossRef]

103. Dias, I.B.; Bouma, H.R.; Henning, R.H. Unraveling the Big Sleep: Molecular Aspects of Stem Cell Dormancy and Hibernation. Front. Physiol. 2021, 12, 624950. [CrossRef]

104. Pisani, D.F.; Dechesne, C.A. Skeletal Muscle HIF-1 $\alpha$ Expression Is Dependent on Muscle Fiber Type. J. Gen. Physiol. 2005, 126, 173-178. [CrossRef] [PubMed]

105. Scheerer, N.; Dehne, N.; Stockmann, C.; Swoboda, S.; Baba, H.A.; Neugebauer, A.; Johnson, R.S.; Fandrey, J. Myeloid hypoxiainducible factor- $1 \alpha$ is essential for skeletal muscle regeneration in mice. J. Immunol. 2013, 191, 407-414. [CrossRef] [PubMed]

106. Yun, Z.; Lin, Q.; Giaccia, A.J. Adaptive Myogenesis under Hypoxia. Mol. Cell. Biol. 2005, 25, 3040-3055. [CrossRef] [PubMed]

107. Majmundar, A.J.; Skuli, N.; Mesquita, R.C.; Kim, M.N.; Yodh, A.G.; Nguyen-McCarty, M.; Simon, M.C. O⿰㇒⿻土一𧘇 Regulates Skeletal Muscle Progenitor Differentiation through Phosphatidylinositol 3-Kinase/AKT Signaling. Mol. Cell. Biol. 2012, 32, 36-49. [CrossRef] [PubMed]

108. Gustafsson, M.V.; Zheng, X.; Pereira, T.; Gradin, K.; Jin, S.; Lundkvist, J.L.; Ruas, J.; Poellinger, L.; Lendahl, U.; Bondesson, M. Hypoxia Requires Notch Signaling to Maintain the Undifferentiated Cell State. Dev. Cell 2005, 9, 617-628. [CrossRef]

109. Wang, C.; Liu, W.; Liu, Z.; Chen, L.; Liu, X.; Kuang, S. Hypoxia Inhibits Myogenic Differentiation through p53 Protein-dependent Induction of Bhlhe40 Protein. J. Biol. Chem. 2015, 290, 29707-29716. [CrossRef] 
110. Launay, T.; Hagstrãm, L.; Lottin-Divoux, S.; Marchant, D.; Quidu, P.; Favret, F.; Duvallet, A.; Darribãre, T.; Richalet, J.P.; Beaudry, M. Blunting effect of hypoxia on the proliferation and differentiation of human primary and rat L6 myoblasts is not counteracted by Epo. Cell Prolif. 2010, 43, 1-8. [CrossRef]

111. Di Carlo, A.; De Mori, R.; Martelli, F.; Pompilio, G.; Capogrossi, M.C.; Germani, A. Hypoxia Inhibits Myogenic Differentiation through Accelerated MyoD Degradation. J. Biol. Chem. 2004, 279, 16332-16338. [CrossRef]

112. Wagatsuma, A.; Arakawa, M.; Matsumoto, H.; Matsuda, R.; Hoshino, T.; Mabuchi, K. Cobalt chloride, a chemical hypoxiamimicking agent, suppresses myoblast differentiation by downregulating myogenin expression. Mol. Cell. Biochem. 2020, 470, 199-214. [CrossRef]

113. Sakushima, K.; Yoshikawa, M.; Osaki, T.; Miyamoto, N.; Hashimoto, T. Moderate hypoxia promotes skeletal muscle cell growth and hypertrophy in C2C12 cells. Biochem. Biophys. Res. Commun. 2020, 525, 921-927. [CrossRef]

114. Muñoz-Sánchez, J.; Chánez-Cárdenas, M.E. The use of cobalt chloride as a chemical hypoxia model. J. Appl. Toxicol. 2019, 39, 556-570. [CrossRef]

115. Kook, S.-H.; Son, Y.-O.; Lee, K.-Y.; Lee, H.-J.; Chung, W.-T.; Choi, K.-C.; Lee, J.-C. Hypoxia affects positively the proliferation of bovine satellite cells and their myogenic differentiation through up-regulation of MyoD. Cell Biol. Int. 2008, 32, 871-878. [CrossRef]

116. Khanna, S.; Roy, S.; Maurer, M.; Ratan, R.R.; Sen, C.K. Oxygen-sensitive reset of hypoxia-inducible factor transactivation response: Prolyl hydroxylases tune the biological normoxic set point. Free Radic. Biol. Med. 2006, 40, 2147-2154. [CrossRef]

117. Carreau, A.; El Hafny-Rahbi, B.; Matejuk, A.; Grillon, C.; Kieda, C. Why is the partial oxygen pressure of human tissues a crucial parameter? Small molecules and hypoxia. J. Cell. Mol. Med. 2011, 15, 1239-1253. [CrossRef]

118. Boekstegers, P.; Riessen, R.; Seyde, W. Oxygen Partial Pressure Distribution Within Skeletal Muscle: Indicator of Whole Body Oxygen Delivery in Patients? Chem. Biol. Pteridines Folates 1990, 277, 507-514. [CrossRef]

119. Ikossi, D.G.; Knudson, M.M.; Morabito, D.J.; Cohen, M.J.; Wan, J.J.; Khaw, L.; Stewart, C.J.; Hemphill, C.; Manley, G.T. Continuous Muscle Tissue Oxygenation in Critically Injured Patients: A Prospective Observational Study. J. Trauma Inj. Infect. Crit. Care 2006, 61, 780-790. [CrossRef]

120. Bylund-Fellenius, A.C.; Walker, P.M.; Elander, A.; Holm, S.; Holm, J.; Scherstén, T. Energy metabolism in relation to oxygen partial pressure in human skeletal muscle during exercise. Biochem. J. 1981, 200, 247-255. [CrossRef]

121. Dubinin, M.V.; Talanov, E.Y.; Tenkov, K.S.; Starinets, V.S.; Mikheeva, I.B.; Sharapov, M.G.; Belosludtsev, K.N. Duchenne muscular dystrophy is associated with the inhibition of calcium uniport in mitochondria and an increased sensitivity of the organelles to the calcium-induced permeability transition. Biochim. Biophys. Acta Mol. Basis Dis. 2020, 1866, 165674. [CrossRef]

122. Jash, S.; Adhya, S. Effects of Transient Hypoxia versus Prolonged Hypoxia on Satellite Cell Proliferation and Differentiation In Vivo. Stem Cells Int. 2015, 2015. [CrossRef]

123. Chaillou, T.; Koulmann, N.; Meunier, A.; Pugnière, P.; McCarthy, J.J.; Beaudry, M.; Bigard, X. Ambient hypoxia enhances the loss of muscle mass after extensive injury. Pflügers Arch. Eur. J. Physiol. 2013, 466, 587-598. [CrossRef] [PubMed]

124. Chaillou, T.; Koulmann, N.; Meunier, A.; Chapot, R.; Serrurier, B.; Beaudry, M.; Bigard, X. Effect of hypoxia exposure on the recovery of skeletal muscle phenotype during regeneration. Mol. Cell. Biochem. 2014, 390, 31-40. [CrossRef]

125. Yanay, N.; Rabie, M.; Nevo, Y. Impaired Regeneration in Dystrophic Muscle-New Target for Therapy. Front. Neurosci. 2020, 13, 69.

126. Banerji, C.R.S.; Henderson, D.; Tawil, R.N.; Zammit, P.S. Skeletal muscle regeneration in facioscapulohumeral muscular dystrophy is correlated with pathological severity. Hum. Mol. Genet. 2020, 29, 2746-2760. [CrossRef]

127. Carregari, V.C.; Monforte, M.; Di Maio, G.; Pieroni, L.; Urbani, A.; Ricci, E.; Tasca, G. Proteomics of Muscle Microdialysates Identifies Potential Circulating Biomarkers in Facioscapulohumeral Muscular Dystrophy. Int. J. Mol. Sci. 2020, 22, 290. [CrossRef]

128. Guiraud, S.; Davies, K.E. Regenerative biomarkers for Duchenne muscular dystrophy. Neural Regen. Res. 2019, 14, 1317-1320. [CrossRef]

129. Dadgar, S.; Wang, Z.; Johnston, H.; Kesari, A.; Nagaraju, K.; Chen, Y.-W.; Hill, D.A.; Partridge, T.A.; Giri, M.; Freishtat, R.; et al. Asynchronous remodeling is a driver of failed regeneration in Duchenne muscular dystrophy. J. Cell Biol. 2014, 207, 139-158. [CrossRef]

130. Bhattacharyya, S.; Kelley, K.; Melichian, D.S.; Tamaki, Z.; Fang, F.; Su, Y.; Feng, G.; Pope, R.M.; Budinger, G.S.; Mutlu, G.M.; et al. Toll-Like Receptor 4 Signaling Augments Transforming Growth Factor- $\beta$ Responses: A Novel Mechanism for Maintaining and Amplifying Fibrosis in Scleroderma. Am. J. Pathol. 2013, 182, 192-205. [CrossRef] [PubMed]

131. Rhoads, R.; Johnson, R.M.; Rathbone, C.R.; Liu, X.; Temm-Grove, C.; Sheehan, S.M.; Hoying, J.B.; Allen, R.E. Satellite cellmediated angiogenesis In Vitro coincides with a functional hypoxia-inducible factor pathway. Am. J. Physiol. Physiol. 2009, 296, C1321-C1328. [CrossRef] [PubMed]

132. Morgan, J.E.; Zammit, P.S. Direct effects of the pathogenic mutation on satellite cell function in muscular dystrophy. Exp. Cell Res. 2010, 316, 3100-3108. [CrossRef]

133. Schiaffino, S.; Reggiani, C. Fiber Types in Mammalian Skeletal Muscles. Physiol. Rev. 2011, 91, 1447-1531. [CrossRef]

134. Mason, S.D.; Howlett, R.A.; Kim, M.J.; Olfert, I.M.; Hogan, M.C.; McNulty, W.; Hickey, R.P.; Wagner, P.D.; Kahn, C.R.; Giordano, F.J.; et al. Loss of Skeletal Muscle HIF-1 $\alpha$ Results in Altered Exercise Endurance. PLoS Biol. 2004, 2, e288. [CrossRef] [PubMed]

135. Mason, S.D.; Rundqvist, H.; Papandreou, I.; Duh, R.; McNulty, W.J.; Howlett, R.A.; Olfert, I.M.; Sundberg, C.J.; Denko, N.C.; Poellinger, L.; et al. HIF- $1 \alpha$ in endurance training: Suppression of oxidative metabolism. Am. J. Physiol. Integr. Comp. Physiol. 2007, 293, R2059-R2069. [CrossRef] 
136. Shin, J.; Nunomiya, A.; Kitajima, Y.; Dan, T.; Miyata, T.; Nagatomi, R. Prolyl hydroxylase domain 2 deficiency promotes skeletal muscle fiber-type transition via a calcineurin/NFATc1-dependent pathway. Skelet. Muscle 2015, 6, 5. [CrossRef]

137. Nunomiya, A.; Shin, J.; Kitajima, Y.; Dan, T.; Miyata, T.; Nagatomi, R. Activation of the hypoxia-inducible factor pathway induced by prolyl hydroxylase domain 2 deficiency enhances the effect of running training in mice. Acta Physiol. 2017, 220, 99-112. [CrossRef] [PubMed]

138. Rasbach, K.A.; Gupta, R.K.; Ruas, J.; Wu, J.; Naseri, E.; Estall, J.; Spiegelman, B.M. PGC-1 regulates a HIF2 -dependent switch in skeletal muscle fiber types. Proc. Natl. Acad. Sci. USA 2010, 107, 21866-21871. [CrossRef]

139. Glaser, J.; Suzuki, M. Skeletal Muscle Fiber Types in Neuromuscular Diseases. In Muscle Cell and Tissue-Current Status of Research Field; InTech Open: London, UK, 2018.

140. Talbot, J.; Maves, L. Skeletal muscle fiber type: Using insights from muscle developmental biology to dissect targets for susceptibility and resistance to muscle disease. Wiley Interdiscip. Rev. Dev. Biol. 2016, 5, 518-534. [CrossRef]

141. Lassche, S.; Stienen, G.J.M.; Irving, T.C.; Van Der Maarel, S.M.; Voermans, N.C.; Padberg, G.W.; Granzier, H.; Van Engelen, B.G.; Ottenheijm, C.A. Sarcomeric dysfunction contributes to muscle weakness in facioscapulohumeral muscular dystrophy. Neurology 2013, 80, 733-737. [CrossRef]

142. Vihola, A.; Bassez, G.; Meola, G.; Zhang, S.; Haapasalo, H.; Paetau, A.; Mancinelli, E.; Rouche, A.; Hogrel, J.; Laforet, P.; et al. Histopathological differences of myotonic dystrophy type 1 (DM1) and PROMM/DM2. Neurology 2003, 60, 1854-1857. [CrossRef]

143. Webster, C.; Silberstein, L.; Hays, A.P.; Blau, H.M. Fast muscle fibers are preferentially affected in Duchenne muscular dystrophy. Cell 1988, 52, 503-513. [CrossRef]

144. Lin, J.; Wu, H.; Tarr, P.T.; Zhang, C.-Y.; Wu, Z.; Boss, O.; Michael, L.F.; Puigserver, P.; Isotani, E.; Olson, E.N.; et al. Transcriptional co-activator PGC-1 $\alpha$ drives the formation of slow-twitch muscle fibres. Nat. Cell Biol. 2002, 418, 797-801. [CrossRef]

145. Handschin, C.; Kobayashi, Y.M.; Chin, S.; Seale, P.; Campbell, K.P.; Spiegelman, B.M. PGC-1 regulates the neuromuscular junction program and ameliorates Duchenne muscular dystrophy. Genes Dev. 2007, 21, 770-783. [CrossRef]

146. Knobloch, M.; Pilz, G.-A.; Ghesquière, B.; Kovacs, W.; Wegleiter, T.; Moore, D.; Hruzova, M.; Zamboni, N.; Carmeliet, P.; Jessberger, S. A Fatty Acid Oxidation-Dependent Metabolic Shift Regulates Adult Neural Stem Cell Activity. Cell Rep. 2017, 20, $2144-2155$. [CrossRef] [PubMed]

147. Ryall, J.G.; Dell'Orso, S.; Derfoul, A.; Juan, A.; Zare, H.; Feng, X.; Clermont, D.; Koulnis, M.; Gutierrez-Cruz, G.; Fulco, M.; et al. The NAD+-Dependent SIRT1 Deacetylase Translates a Metabolic Switch into Regulatory Epigenetics in Skeletal Muscle Stem Cells. Cell Stem Cell 2015, 16, 171-183. [CrossRef]

148. Bose, S.; Zhang, C.; Le, A. Glucose Metabolism in Cancer: The Warburg Effect and Beyond. In The Heterogeneity of Cancer Metabolism; Le, A., Ed.; Springer: Chem, Switzerland, 2021; Volume 1311, pp. 3-15.

149. Mason, S.; Johnson, R.S. The role of HIF-1 in Hypoxic Response in the Skeletal Muscle. In Hypoxia and the Circulation; Roach, R.C., Wagner, P.D., Hackett, P.H., Eds.; Springer Science and Business Media LLC: Boston, MA, USA, 2007; Volume 618, pp. 229-244.

150. Egan, B.; Zierath, J.R. Exercise Metabolism and the Molecular Regulation of Skeletal Muscle Adaptation. Cell Metab. 2013, 17, 162-184. [CrossRef]

151. Semenza, G.L. $\mathrm{O}_{2}$, and the 3 PHDs: How Animal Cells Signal Hypoxia to the Nucleus. Cell 2001, 107, 1-3. [CrossRef]

152. Horscroft, J.A.; Murray, A.J. Skeletal muscle energy metabolism in environmental hypoxia: Climbing towards consensus. Extrem. Physiol. Med. 2014, 3, 1-17. [CrossRef]

153. De Palma, S.; Ripamonti, M.; Viganò, A.; Moriggi, M.; Capitanio, D.; Samaja, M.; Milano, G.; Cerretelli, P.; Wait, R.; Gelfi, C. Metabolic Modulation Induced by Chronic Hypoxia in Rats Using a Comparative Proteomic Analysis of Skeletal Muscle Tissue. J. Proteome Res. 2007, 6, 1974-1984. [CrossRef] [PubMed]

154. Lindholm, M.E.; Fischer, H.; Poellinger, L.; Johnson, R.S.; Gustafsson, T.; Sundberg, C.J.; Rundqvist, H. Negative regulation of HIF in skeletal muscle of elite endurance athletes: A tentative mechanism promoting oxidative metabolism. Am. J. Physiol. Integr. Comp. Physiol. 2014, 307, R248-R255. [CrossRef]

155. Green, H.J.; Sutton, J.R.; Wolfel, E.E.; Reeves, J.T.; Butterfield, G.E.; Brooks, G.A. Altitude acclimatization and energy metabolic adaptations in skeletal muscle during exercise. J. Appl. Physiol. 1992, 73, 2701-2708. [CrossRef] [PubMed]

156. Brooks, G.A.; Wolfel, E.E.; Butterfield, G.E.; Cymerman, A.; Roberts, A.C.; Mazzeo, R.S.; Reeves, J.T. Poor relationship between arterial [lactate] and leg net release during exercise at $4300 \mathrm{~m}$ altitude. Am. J. Physiol. Integr. Comp. Physiol. 1998, 275 , R1192-R1201. [CrossRef]

157. Liu, Y.; Ma, Z.; Zhao, C.; Wang, Y.; Wu, G.; Xiao, J.; McClain, C.J.; Li, X.; Feng, W. HIF-1 $\alpha$ and HIF- $2 \alpha$ are critically involved in hypoxia-induced lipid accumulation in hepatocytes through reducing PGC-1 $\alpha$-mediated fatty acid $\beta$-oxidation. Toxicol. Lett. 2014, 226, 117-123. [CrossRef] [PubMed]

158. Chicco, A.J.; Le, C.H.; Gnaiger, E.; Dreyer, H.C.; Muyskens, J.B.; D'Alessandro, A.; Nemkov, T.; Hocker, A.D.; Prenni, J.E.; Wolfe, L.M.; et al. Adaptive remodeling of skeletal muscle energy metabolism in high-altitude hypoxia: Lessons from AltitudeOmics. J. Biol. Chem. 2018, 293, 6659-6671. [CrossRef] [PubMed]

159. Zhang, H.; Bosch-Marce, M.; Shimoda, L.A.; Tan, Y.S.; Baek, J.H.; Wesley, J.B.; Gonzalez, F.J.; Semenza, G.L. Mitochondrial Autophagy Is an HIF-1-dependent Adaptive Metabolic Response to Hypoxia. J. Biol. Chem. 2008, 283, 10892-10903. [CrossRef] [PubMed]

160. Bloemberg, D.; Quadrilatero, J. Autophagy, apoptosis, and mitochondria: Molecular integration and physiological relevance in skeletal muscle. Am. J. Physiol. Physiol. 2019, 317, C111-C130. [CrossRef] 
161. Band, M.; Joel, A.; Hernandez, A.; Avivi, A. Hypoxia-induced BNIP3 expression and mitophagy: In Vivo comparison of the rat and the hypoxia-tolerant mole rat, Spalax ehrenbergi. FASEB J. 2009, 23, 2327-2335. [CrossRef]

162. Gamboa, J.L.; García-Cazarín, M.L.; Andrade, F.H. Chronic hypoxia increases insulin-stimulated glucose uptake in mouse soleus muscle. Am. J. Physiol. Integr. Comp. Physiol. 2011, 300, R85-R91. [CrossRef] [PubMed]

163. De Theije, C.C.; Langen, R.C.J.; Lamers, W.H.; Schols, A.M.W.J.; Köhler, S.E. Distinct responses of protein turnover regulatory pathways in hypoxia- and semistarvation-induced muscle atrophy. Am. J. Physiol. Cell. Mol. Physiol. 2013, 305, L82-L91. [CrossRef]

164. Chen, R.; Jiang, T.; She, Y.; Xu, J.; Li, C.; Zhou, S.; Shen, H.; Shi, H.; Liu, S. Effects of Cobalt Chloride, a Hypoxia-Mimetic Agent, on Autophagy and Atrophy in Skeletal C2C12 Myotubes. BioMed. Res. Int. 2017, 2017. [CrossRef]

165. Dreyfus, J.-C.; Schapira, G.; Schapira, F.; Demos, J. Activités enzymatiques du muscle humain: Recherches sur la biochimie comparée de l'homme normal et myopathique, et du rat. Clin. Chim. Acta 1956, 1, 434-449. [CrossRef]

166. Pant, M.; Sopariwala, D.H.; Bal, N.C.; Lowe, J.; Delfín, D.A.; Rafael-Fortney, J.; Periasamy, M. Metabolic Dysfunction and Altered Mitochondrial Dynamics in the Utrophin-Dystrophin Deficient Mouse Model of Duchenne Muscular Dystrophy. PLoS ONE 2015, 10, e0123875. [CrossRef]

167. Nghiem, P.P.; Bello, L.; Stoughton, W.B.; López, S.M.; Vidal, A.; Hernandez, B.V.; Hulbert, K.N.; Gourley, T.R.; Bettis, A.K.; Balog-Alvarez, C.J.; et al. Changes in Muscle Metabolism are Associated with Phenotypic Variability in Golden Retriever Muscular Dystrophy. Yale J. Biol. Med. 2017, 90, 351-360.

168. Schneider, S.M.; Sridhar, V.; Bettis, A.K.; Heath-Barnett, H.; Balog-Alvarez, C.J.; Guo, L.-J.; Johnson, R.; Jaques, S.; Vitha, S.; Glowcwski, A.C.; et al. Glucose Metabolism as a Pre-clinical Biomarker for the Golden Retriever Model of Duchenne Muscular Dystrophy. Mol. Imaging Biol. 2018, 20, 780-788. [CrossRef]

169. Rodríiguez-Cruz, M.; Sanchez, R.; Escobar, R.E.; Del Cruz-Guzmáan, O.R.; Lóopez-Alarcóon, M.; Bernabe-Garcíia, M.; CoralVáazquez, R.M.; Matute, G.; Wong, A.C.V. Evidence of Insulin Resistance and Other Metabolic Alterations in Boys with Duchenne or Becker Muscular Dystrophy. Int. J. Endocrinol. 2015, 2015. [CrossRef] [PubMed]

170. Matsumura, T.; Iwahashi, H.; Funahashi, T.; Takahashi, M.P.; Saito, T.; Yasui, K.; Saito, T.; Iyama, A.; Toyooka, K.; Fujimura, H.; et al. A cross-sectional study for glucose intolerance of myotonic dystrophy. J. Neurol. Sci. 2009, 276, 60-65. [CrossRef] [PubMed]

171. Srivastava, N.K.; Yadav, R.; Mukherjee, S.; Sinha, N. Perturbation of muscle metabolism in patients with muscular dystrophy in early or acute phase of disease: In Vitro, high resolution NMR spectroscopy based analysis. Clin. Chim. Acta 2018, 478, 171-181. [CrossRef] [PubMed]

172. Turki, A.; Hayot, M.; Carnac, G.; Pillard, F.; Passerieux, E.; Bommart, S.; de Mauverger, E.R.; Hugon, G.; Pincemail, J.; Pietri, S.; et al. Functional muscle impairment in facioscapulohumeral muscular dystrophy is correlated with oxidative stress and mitochondrial dysfunction. Free Radic. Biol. Med. 2012, 53, 1068-1079. [CrossRef] [PubMed]

173. Banerji, C.R.S.; Panamarova, M.; Pruller, J.; Figeac, N.; Hebaishi, H.; Fidanis, E.; Saxena, A.; Contet, J.; Sacconi, S.; Severini, S.; et al. Dynamic transcriptomic analysis reveals suppression of PGC1 $\alpha / E R R \alpha$ drives perturbed myogenesis in facioscapulohumeral muscular dystrophy. Hum. Mol. Genet. 2019, 28, 1244-1259. [CrossRef]

174. Orsucci, D.; Ienco, E.C.; Rossi, A.; Siciliano, G.; Mancuso, M. Mitochondrial Syndromes Revisited. J. Clin. Med. 2021, 10, 1249. [CrossRef]

175. Barbieri, E.; Sestili, P. Reactive Oxygen Species in Skeletal Muscle Signaling. J. Signal. Transduct. 2012, 2012. [CrossRef]

176. Mason, S.; Wadley, G.D. Skeletal muscle reactive oxygen species: A target of good cop/bad cop for exercise and disease. Redox Rep. 2014, 19, 97-106. [CrossRef]

177. He, F.; Li, J.; Liu, Z.; Chuang, C.-C.; Yang, W.; Zuo, L. Redox Mechanism of Reactive Oxygen Species in Exercise. Front. Physiol. 2016, 7. [CrossRef]

178. Pan, J.-S.; Hong, M.-Z.; Ren, J.-L. Reactive oxygen species: A double-edged sword in oncogenesis. World J. Gastroenterol. 2009, 15, 1702-1707. [CrossRef]

179. Singh, S.N.; Vats, P.; Kumria, M.M.L.; Ranganathan, S.; Shyam, R.; Arora, M.P.; Jain, C.L.; Sridharan, K. Effect of high altitude (7620 m) exposure on glutathione and related metabolism in rats. Graefe's Arch. Clin. Exp. Ophthalmol. 2001, 84, 233-237. [CrossRef]

180. Magalhães, J.; Ascensão, A.; Soares, J.M.C.; Ferreira, R.; Neuparth, M.J.; Marques, F.; Duarte, J.A. Acute and severe hypobaric hypoxia increases oxidative stress and impairs mitochondrial function in mouse skeletal muscle. J. Appl. Physiol. 2005, 99, 1247-1253. [CrossRef] [PubMed]

181. Neuparth, M.J.; Ferreira, R.; Amado, F.; Magalhães, J.; Ascensão, A.; Soares, J.M.C.; Oliveira, J.; Duarte, J.A. Acute and severe hypobaric hypoxia-induced muscle oxidative stress in mice: The role of glutathione against oxidative damage. Graefe's Arch. Clin. Exp. Ophthalmol. 2003, 91, 185-191. [CrossRef]

182. Faiss, R.; Pialoux, V.; Sartori, C.; Faes, C.; Dériaz, O.; Millet, G. Ventilation, Oxidative Stress, and Nitric Oxide in Hypobaric versus Normobaric Hypoxia. Med. Sci. Sports Exerc. 2013, 45, 253-260. [CrossRef]

183. Pialoux, V.; Mounier, R.; Rock, E.; Mazur, A.; Schmitt, L.; Richalet, J.-P.; Robach, P.; Coudert, J.; Fellmann, N. Effects of Acute Hypoxic Exposure on Prooxidant/Antioxidant Balance in Elite Endurance Athletes. Int. J. Sports Med. 2009, 30, 87-93. [CrossRef]

184. Magalhães, J.; Ascensão, A.; Viscor, G.; Soares, J.; Oliveira, J.; Marques, F.; Duarte, J. Oxidative stress in humans during and after 4 hours of hypoxia at a simulated altitude of $5500 \mathrm{~m}$. Aviat. Space Environ. Med. 2004, 75, 16-22.

185. Dosek, A.; Ohno, H.; Acs, Z.; Taylor, A.W.; Radak, Z. High altitude and oxidative stress. Respir. Physiol. Neurobiol. 2007, 158, 128-131. [CrossRef] 
186. Debevec, T.; Pialoux, V.; Saugy, J.J.; Schmitt, L.; Cejuela, R.; Mury, P.; Ehrström, S.; Faiss, R.; Millet, G.P. Prooxidant/ Antioxidant Balance in Hypoxia: A Cross-Over Study on Normobaric vs. Hypobaric “Live High-Train Low”. PLoS ONE 2015, 10 , e0137957. [CrossRef]

187. Debevec, T.; Pialoux, V.; Mekjavic, I.; Eiken, O.; Mury, P.; Millet, G. Moderate Exercise Blunts Oxidative Stress Induced by Normobaric Hypoxic Confinement. Med. Sci. Sports Exerc. 2014, 46, 33-41. [CrossRef]

188. Wright, V.P.; Klawitter, P.F.; Iscru, D.F.; Merola, A.J.; Clanton, T.L. Superoxide scavengers augment contractile but not energetic responses to hypoxia in rat diaphragm. J. Appl. Physiol. 2005, 98, 1753-1760. [CrossRef]

189. Mohanraj, P.; Merola, A.J.; Wright, V.P.; Clanton, T. Antioxidants protect rat diaphragmatic muscle function under hypoxic conditions. J. Appl. Physiol. 1998, 84, 1960-1966. [CrossRef]

190. Quindry, J.; Dumke, C.; Slivka, D.; Ruby, B. Impact of extreme exercise at high altitude on oxidative stress in humans. J. Physiol. 2016, 594, 5093-5104. [CrossRef]

191. Cofta, S.; Winiarska, H.M.; Płóciniczak, A.; Bielawska, L.; Brożek, A.; Piorunek, T.; Kostrzewska, T.M.; Wysocka, E. Oxidative Stress Markers and Severity of Obstructive Sleep Apnea. Adv. Exp. Med. Biol. 2019, 1222, 27-35. [CrossRef]

192. Conotte, S.; Tassin, A.; Conotte, R.; Colet, J.-M.; Boudjeltia, K.Z.; Legrand, A. Metabonomic profiling of chronic intermittent hypoxia in a mouse model. Respir. Physiol. Neurobiol. 2018, 256, 157-173. [CrossRef]

193. Dunleavy, M.; Bradford, A.; O'Halloran, K.D. Oxidative Stress Impairs Upper Airway Muscle Endurance in an Animal Model of Sleep-Disordered Breathing. In Integration in Respiratory Control: From Genes to Systems; Poulin, M.J., Wilson, R.J.A., Eds.; Springer: New York, NY, USA, 2008; pp. 458-462. ISBN 978-0-387-73693-8.

194. Dutta, A.; Ray, K.; Singh, V.K.; Vats, P.; Singh, S.N.; Singh, S.B. l-carnitine supplementation attenuates intermittent hypoxiainduced oxidative stress and delays muscle fatigue in rats. Exp. Physiol. 2008, 93, 1139-1146. [CrossRef] [PubMed]

195. Skelly, J.R.; Edge, D.; Shortt, C.M.; Jones, J.F.X.; Bradford, A.; O’Halloran, K.D. Tempol Ameliorates Pharyngeal Dilator Muscle Dysfunction in a Rodent Model of Chronic Intermittent Hypoxia. Am. J. Respir. Cell Mol. Biol. 2012, 46, 139-148. [CrossRef] [PubMed]

196. Bradford, A.; McGuire, M.; O’Halloran, K.D. Does episodic hypoxia affect upper airway dilator muscle function? Implications for the pathophysiology of obstructive sleep apnoea. Respir. Physiol. Neurobiol. 2005, 147, 223-234. [CrossRef] [PubMed]

197. Shortt, C.M.; Fredsted, A.; Chow, H.B.; Williams, R.; Skelly, J.R.; Edge, D.; Bradford, A.; O’Halloran, K.D. Reactive oxygen species mediated diaphragm fatigue in a rat model of chronic intermittent hypoxia. Exp. Physiol. 2014, 99, 688-700. [CrossRef]

198. McGuire, M.; MacDermott, M.; Bradford, A. Effects of Chronic Intermittent Asphyxia on Rat Diaphragm and Limb Muscle Contractility. Chest 2003, 123, 875-881. [CrossRef] [PubMed]

199. Huang, S.; Jin, L.; Shen, J.; Shang, P.; Jiang, X.; Wang, X. Electrical stimulation influences chronic intermittent hypoxia-hypercapnia induction of muscle fibre transformation by regulating the microRNA/Sox6 pathway. Sci. Rep. 2016, 6, 26415. [CrossRef]

200. Domínguez-Álvarez, M.; Gea, J.; Barreiro, E. Inflammatory Events and Oxidant Production in the Diaphragm, Gastrocnemius, and Blood of Rats Exposed to Chronic Intermittent Hypoxia: Therapeutic Strategies. J. Cell. Physiol. 2017, 232, 1165-1175. [CrossRef]

201. Petrillo, S.; Pelosi, L.; Piemonte, F.; Travaglini, L.; Forcina, L.; Catteruccia, M.; Petrini, S.; Verardo, M.; D'Amico, A.; Musarò, A.; et al. Oxidative stress in Duchenne muscular dystrophy: Focus on the NRF2 redox pathway. Hum. Mol. Genet. 2017, 26, 2781-2790. [CrossRef]

202. Passerieux, E.; Hayot, M.; Jaussent, A.; Carnac, G.; Gouzi, F.; Pillard, F.; Picot, M.-C.; Böcker, K.; Hugon, G.; Pincemail, J.; et al. Effects of vitamin C, vitamin E, zinc gluconate, and selenomethionine supplementation on muscle function and oxidative stress biomarkers in patients with facioscapulohumeral dystrophy: A double-blind randomized controlled clinical trial. Free Radic. Biol. Med. 2015, 81, 158-169. [CrossRef] [PubMed]

203. Laoudj-Chenivesse, D.; Carnac, G.; Bisbal, C.; Hugon, G.; Bouillot, S.; Desnuelle, C.; Vassetzky, Y.; Fernandez, A. Increased levels of adenine nucleotide translocator 1 protein and response to oxidative stress are early events in facioscapulohumeral muscular dystrophy muscle. J. Mol. Med. 2004, 83, 216-224. [CrossRef] [PubMed]

204. Denny, A.P.; Heather, A.K. Are Antioxidants a Potential Therapy for FSHD? A Review of the Literature. Oxidative Med. Cell. Longev. 2017, 2017, 7020295. [CrossRef]

205. Arbogast, S.; Beuvin, M.; Fraysse, B.; Zhou, H.; Muntoni, F.; Ferreiro, A. Oxidative stress inSEPN1-related myopathy: From pathophysiology to treatment. Ann. Neurol. 2009, 65, 677-686. [CrossRef]

206. Terrill, J.R.; Radley-Crabb, H.G.; Iwasaki, T.; Lemckert, F.A.; Arthur, P.G.; Grounds, M.D. Oxidative stress and pathology in muscular dystrophies: Focus on protein thiol oxidation and dysferlinopathies. FEBS J. 2013, 280, 4149-4164. [CrossRef]

207. Sieprath, T.; Darwiche, R.; De Vos, W.H. Lamins as mediators of oxidative stress. Biochem. Biophys. Res. Commun. 2012, 421, 635-639. [CrossRef]

208. Dudley, R.W.R.; Khairallah, M.; Mohammed, S.; Lands, L.; Des Rosiers, C.; Petrof, B.J. Dynamic responses of the glutathione system to acute oxidative stress in dystrophic mouse (mdx) muscles. Am. J. Physiol. Integr. Comp. Physiol. 2006, 291, R704-R710. [CrossRef]

209. Renjini, R.; Gayathri, N.; Nalini, A.; Bharath, M.M.S. Oxidative Damage in Muscular Dystrophy Correlates with the Severity of the Pathology: Role of Glutathione Metabolism. Neurochem. Res. 2012, 37, 885-898. [CrossRef]

210. Kaczor, J.; Hall, J.E.; Payne, E.; Tarnopolsky, M.A. Low intensity training decreases markers of oxidative stress in skeletal muscle of mdx mice. Free Radic. Biol. Med. 2007, 43, 145-154. [CrossRef] 
211. Selsby, J.T. Increased catalase expression improves muscle function in mdx mice. Exp. Physiol. 2010, 96, 194-202. [CrossRef]

212. Hori, Y.S.; Kuno, A.; Hosoda, R.; Tanno, M.; Miura, T.; Shimamoto, K.; Horio, Y. Resveratrol Ameliorates Muscular Pathology in the Dystrophic mdx Mouse, a Model for Duchenne Muscular Dystrophy. J. Pharmacol. Exp. Ther. 2011, 338, 784-794. [CrossRef]

213. Call, J.A.; Voelker, K.A.; Wolff, A.V.; McMillan, R.P.; Evans, N.P.; Hulver, M.W.; Talmadge, R.J.; Grange, R.W. Endurance capacity in maturing $\mathrm{mdx}$ mice is markedly enhanced by combined voluntary wheel running and green tea extract. J. Appl. Physiol. 2008, 105, 923-932. [CrossRef]

214. Buetler, T.M.; Renard, M.; Offord, E.A.; Schneider, H.; Ruegg, U.T. Green tea extract decreases muscle necrosis in mdx mice and protects against reactive oxygen species. Am. J. Clin. Nutr. 2002, 75, 749-753. [CrossRef]

215. Buyse, G.M.; Voit, T.; Schara, U.; Straathof, C.S.M.; D'Angelo, M.G.; Bernert, G.; Cuisset, J.-M.; Finkel, R.S.; Goemans, N.; McDonald, C.M.; et al. Efficacy of idebenone on respiratory function in patients with Duchenne muscular dystrophy not using glucocorticoids (DELOS): A double-blind randomised placebo-controlled phase 3 trial. Lancet 2015, 385, 1748-1757. [CrossRef]

216. Buyse, G.M.; Goemans, N.; van den Hauwe, M.; Meier, T. Effects of glucocorticoids and idebenone on respiratory function in patients with duchenne muscular dystrophy. Pediatr. Pulmonol. 2013, 48, 912-920. [CrossRef]

217. Buyse, G.M.; Goemans, N.; van den Hauwe, M.; Thijs, D.; de Groot, I.J.; Schara, U.; Ceulemans, B.; Meier, T.; Mertens, L. Idebenone as a novel, therapeutic approach for Duchenne muscular dystrophy: Results from a 12 month, double-blind, randomized placebocontrolled trial. Neuromuscul. Disord. 2011, 21, 396-405. [CrossRef]

218. Winokur, S.T.; Barrett, K.; Martin, J.H.; Forrester, J.R.; Simon, M.; Tawil, R.; Chung, S.-A.; Masny, P.S.; Figlewicz, D.A. Facioscapulohumeral muscular dystrophy (FSHD) myoblasts demonstrate increased susceptibility to oxidative stress. Neuromuscul. Disord. 2003, 13, 322-333. [CrossRef]

219. Wilson, V.D.; Thomas, C.; Passerieux, E.; Hugon, G.; Pillard, F.; Andrade, A.G.P.; Bommart, S.; Picot, M.-C.; Pincemail, J.; Mercier, J.; et al. Impaired oxygen demand during exercise is related to oxidative stress and muscle function in Facioscapulohumeral Muscular Dystrophy. JCSM Rapid Commun. 2018, 1, 1-13. [CrossRef]

220. Sasaki-Honda, M.; Jonouchi, T.; Arai, M.; Hotta, A.; Mitsuhashi, S.; Nishino, I.; Matsuda, R.; Sakurai, H. A patient-derived iPSC model revealed oxidative stress increases facioscapulohumeral muscular dystrophy-causative DUX4. Hum. Mol. Genet. 2018, 27, 4024-4035. [CrossRef] [PubMed]

221. Karpukhina, A.; Galkin, I.; Ma, Y.; Dib, C.; Zinovkin, R.; Pletjushkina, O.; Chernyak, B.; Popova, E.; Vassetzky, Y. Analysis of genes regulated by DUX4 via oxidative stress reveals potential therapeutic targets for treatment of facioscapulohumeral dystrophy. Redox Biol. 2021, 43, 102008. [CrossRef] [PubMed]

222. Rudolf, R.; Magalhães, P.J.; Pozzan, T. Direct in vivo monitoring of sarcoplasmic reticulum Ca2+ and cytosolic cAMP dynamics in mouse skeletal muscle. J. Cell Biol. 2006, 173, 187-193. [CrossRef] [PubMed]

223. Stoyanovsky, D.; Murphy, T.; Anno, P.R.; Kim, Y.-M.; Salama, G. Nitric oxide activates skeletal and cardiac ryanodine receptors. Cell Calcium 1997, 21, 19-29. [CrossRef]

224. Coirault, C.; Guellich, A.; Barbry, T.; Samuel, J.-L.; Riou, B.; LeCarpentier, Y. Oxidative stress of myosin contributes to skeletal muscle dysfunction in rats with chronic heart failure. Am. J. Physiol. Circ. Physiol. 2007, 292, H1009-H1017. [CrossRef] [PubMed]

225. Yamada, T.; Mishima, T.; Sakamoto, M.; Sugiyama, M.; Matsunaga, S.; Wada, M. Oxidation of myosin heavy chain and reduction in force production in hyperthyroid rat soleus. J. Appl. Physiol. 2006, 100, 1520-1526. [CrossRef]

226. De Brotto, M.P.; Van Leyen, S.; Brotto, L.S.; Jin, J.-P.; Nosek, C.M.; Nosek, T.M. Hypoxia/fatigue-induced degradation of troponin I and troponin C: New insights into physiologic muscle fatigue. Pflügers Arch. Eur. J. Physiol. 2001, 442, 738-744. [CrossRef]

227. Kaneko, M.; Suzuki, H.; Masuda, H.; Yuan, G.; Hayashi, H.; Kobayashi, A.; Yamazaki, N. Effects of oxygen free radicals on Ca ${ }^{2+}$ binding to cardiac troponin. Jpn. Circ. J. 1992, 56, 1288-1290. [CrossRef]

228. Kanatous, S.B.; Mammen, P.P.A.; Rosenberg, P.B.; Martin, C.M.; White, M.D.; DiMaio, J.M.; Huang, G.; Muallem, S.; Garry, D.J. Hypoxia reprograms calcium signaling and regulates myoglobin expression. Am. J. Physiol. Physiol. 2009, 296, C393-C402. [CrossRef]

229. Aley, P.K.; Porter, K.E.; Boyle, J.P.; Kemp, P.J.; Peers, C. Hypoxic Modulation of Ca ${ }^{2+}$ Signaling in Human Venous Endothelial Cells. J. Biol. Chem. 2005, 280, 13349-13354. [CrossRef]

230. Chen, L.; Lu, X.-Y.; Li, J.; Fu, J.-D.; Zhou, Z.-N.; Yang, H.-T. Intermittent hypoxia protects cardiomyocytes against ischemiareperfusion injury-induced alterations in $\mathrm{Ca}^{2+}$ homeostasis and contraction via the sarcoplasmic reticulum and $\mathrm{Na}^{+} / \mathrm{Ca}^{2+}$ exchange mechanisms. Am. J. Physiol. Cell Physiol. 2006, 290, C1221-C1229. [CrossRef]

231. Briguet, A.; Erb, M.; Courdier-Fruh, I.; Barzaghi, P.; Santos, G.; Herzner, H.; Lescop, C.; Siendt, H.; Henneboehle, M.; Weyermann, P.; et al. Effect of calpain and proteasome inhibition on $\mathrm{Ca}^{2+}$-dependent proteolysis and muscle histopathology in the mdx mouse. FASEB J. 2008, 22, 4190-4200. [CrossRef]

232. Tidball, J.G.; Spencer, M.J. Calpains and muscular dystrophies. Int. J. Biochem. Cell Biol. 2000, 32, 1-5. [CrossRef]

233. Lohan, J.; Ohlendieck, K. Drastic reduction in the luminal $\mathrm{Ca}^{2+}$-binding proteins calsequestrin and sarcalumenin in dystrophindeficient cardiac muscle. Biochim. Biophys. Acta Mol. Basis Dis. 2004, 1689, 252-258. [CrossRef] [PubMed]

234. Culligan, K.; Banville, N.; Dowling, P.; Ohlendieck, K. Drastic reduction of calsequestrin-like proteins and impaired calcium binding in dystrophic mdx muscle. J. Appl. Physiol. 2002, 92, 435-445. [CrossRef]

235. Gyawali, B.; Shimokata, T.; Honda, K.; Kondoh, C.; Hayashi, N.; Yoshino, Y.; Sassa, N.; Nakano, Y.; Gotoh, M.; Ando, Y. Muscle wasting associated with the long-term use of mTOR inhibitors. Mol. Clin. Oncol. 2016, 5, 641-646. [CrossRef] 
236. Cohen, J.; DeSimone, A.; Lek, M.; Lek, A. Therapeutic Approaches in Facioscapulohumeral Muscular Dystrophy. Trends Mol. Med. 2021, 27, 123-137. [CrossRef]

237. Bosnakovski, D.; Xu, Z.; Gang, E.J.; Galindo, C.L.; Liu, M.; Simsek, T.; Garner, H.R.; Agha-Mohammadi, S.; Tassin, A.; Coppée, F.; et al. An isogenetic myoblast expression screen identifies DUX4-mediated FSHD-associated molecular pathologies. EMBO J. 2008, 27, 2766-2779. [CrossRef]

238. Bosnakovski, D.; Choi, S.H.; Strasser, J.M.; Toso, E.A.; Walters, M.A.; Kyba, M. High-throughput screening identifies inhibitors of DUX4-induced myoblast toxicity. Skelet. Muscle 2014, 4, 4. [CrossRef] [PubMed] 